\title{
11
}

\section{Planetary Aeolian Geomorphology}

\author{
Mary C. Bourke ${ }^{1}$, Matthew Balme ${ }^{2}$, Stephen Lewis ${ }^{2}$, Ralph D. Lorenz ${ }^{3}$, and Eric Parteli \\ ${ }^{1}$ Trinity College, Dublin, Ireland \\ ${ }^{2}$ The Open University, Milton Keynes, UK \\ ${ }^{3}$ Johns Hopkins University, Laurel, Maryland, USA \\ ${ }^{4}$ University of Cologne, Cologne, Germany
}

\subsection{Introduction}

Aeolian processes play an essential role not only in the dynamics of beaches and deserts on the Earth, but also contribute to surface landforms on several bodies in our solar system.

\subsection{Planetary Atmospheres}

There are at least four bodies in our solar system that have sufficient enough atmosphere to sustain winds that can transport sediment: Mars, Titan, Venus, and Earth. These atmospheres interact with geological processes and influence the morphology and composition of surfaces (Grotzinger et al. 2013).

\subsubsection{Mars}

Landforms and geochemical signatures suggest that the atmosphere of Mars was significantly thicker in its past, even as Mars today has the thinnest atmosphere of all the bodies that contain confirmed aeolian features. On Mars. the orbital parameters of eccentricity, obliquity, and season of perihelion are more variable than on Earth, leading to a strongly forced global climate that has varied significantly through time (Laskar et al. 2004).

As on Earth, atmospheric circulation patterns on Mars are generated by air flows at many different scales, varying spatially, and seasonally. Martian global wind patterns are derived from Hadley cells. Also, baroclinic instability on Mars is produced by an obliquity and rotation similar to Earth (see Table 11.1). Air rises at intertropical convergence zones (ITCZ) and sinks at the poles. Unlike Earth, however, the Hadley cells are of unequal size in different seasons as the Martian ITCZ shifts latitudinally due to the rapid thermal response of the surface. For example, at the solstices, the summer hemisphere Hadley cell crosses the equator and sinks in the winter hemisphere. The resultant surface winds are, like Earth, deflected to the west as they approach the equator by a Coriolis effect. The significantly higher elevations in the southern hemisphere together with severe eccentricities (see Table 11.1), in which the perihelion occurs during the southern summer, contribute to a stronger 
Table 11.1 Properties of planetary atmospheres and surfaces.

\begin{tabular}{|c|c|c|c|c|}
\hline Body & Venus & Earth & Mars & Titan \\
\hline Mean distance from sun (AU) & 0.72 & 1 & 1.52 & 9.58 \\
\hline Diameter $(\mathrm{Km})$ & 12104 & 12742 & 6779 & 5150 \\
\hline Gravitational acceleration $\left(\mathrm{m} \mathrm{s}^{-2}\right)$ & 8.87 & 9.81 & 3.71 & 1.35 \\
\hline Rotation period (sidereal day) & 223 & 1 & 1.04 & 16 \\
\hline Mean surface atmospheric pressure (bar) & 91 & 1.01 & 0.007 & 1.47 \\
\hline Mean surface air temperature $\left({ }^{\circ} \mathrm{C}\right)$ & 464 & 15 & -63 & -178 \\
\hline Dominant atmospheric gas & $\mathrm{CO}_{2}$ & $\mathrm{~N} 2, \mathrm{O}_{2}$ & $\mathrm{CO}_{2}$ & $\mathrm{~N}_{2}, \mathrm{CH}_{4}$ \\
\hline Atmospheric density $\left(\mathrm{kg} \mathrm{m}^{-3}\right)$ & 64 & 1.25 & 0.02 & 5.4 \\
\hline Dynamic viscosity $\left(10^{-6} \mathrm{~Pa}-\mathrm{s}\right)$ & 35 & 17 & 13 & 6 \\
\hline Planetary boundary layer (km) & $0.2 ?$ & $0.3-3$ & $>10$ & $2-3$ \\
\hline Total topographic relief $(\mathrm{km})$ & 13.7 & 19.8 & 29.4 & $\sim 0.5$ \\
\hline Minimum threshold friction speed $\left(\mathrm{ms}^{-1}\right)^{a}$ & 0.02 & 0.2 & 2.0 & 0.04 \\
\hline Dune field cover $\left(\times 10^{6} \mathrm{~km}^{2}\right)^{b}$ & 0.0183 & 5 & 0.9 & 10 \\
\hline Dune field cover (\% land and ocean surface area) ${ }^{c}$ & 0.004 & 0.98 & 0.62 & 12.5 \\
\hline
\end{tabular}

${ }^{a}$ Greeley and Iverson (1985).

${ }^{b}$ Estimates from Greeley et al. (1995), Livingstone and Warren (1996), Fenton and Hayward (2010), Le Gall et al. (2011).

${ }^{c}$ Source: After Fenton et al. (2013).

Hadley circulation during the southern summer than in the northern. Thus, the largest dust storms on Mars occur during the southern summer.

However, it should be noted that there is also a significant variability of atmospheric pressure on Mars at the seasonal scale. During the Martian winter, atmospheric temperatures move below the condensation point of $\mathrm{CO}_{2}$. This results in a drop of atmospheric pressure by $30 \%$ over a Mars year as the seasonal $\mathrm{CO}_{2}$ ice cap forms. These periods of low pressure depress the conditions for saltation globally while the aeolian deposits are sequestered under their seasonal ice caps at the poles. The seasonal ice caps are deposited down to approximately $55^{\circ} \mathrm{N}$ and $50^{\circ} \mathrm{S}$. Wintertime jet streams that generate westerly winds and fronts are produced by the strong thermal contrasts at the edges of these polar caps. These are particularly effective in areas of low topographic roughness such as the northern plains. During the springtime sublimation of these seasonal caps, off-cap katabatic winds are generated.

There is significant difference in the elevation of the southern hemisphere on Mars to the lower (by several kilometres) northern hemisphere. Atmospheric pressure and density vary considerable across these topographic heights on Mars. For example, atmospheric pressure at the base of the Tharsis Volcanoes is $6 \mathrm{mb}$, and this drops by a factor of almost 6 at the $22 \mathrm{~km}$ high summit of the volcanoes. This is reflected in the larger wavelength of bedforms on the volcanic peaks (Lorenz et al. 2014). Topographic forcing at canyon walls, crater rims, and volcanic peaks produces geomorphologically significant slope winds that can generate net upslope flow during the day and downslope flow during the night. The enhanced wind velocities generated by topographic forcing may create areas of enhanced sediment transport on Mars (Bourke et al. 2004; Jackson et al. 2015). On a diurnal scale, surface heating leads 
to convective generation of wind gusts and dust devils (see Section 11.6.1).

\subsubsection{Titan}

Saturn dominates the global circulation patterns, length of year, and seasons on its moon, Titan. A year on Titan is 29.46 terrestrial years, and the small rotation rate of Titan ( 1 Titan day $=15.95$ Earth days) inhibits mid and high-latitude baroclinic instability. The eccentric orbit (0.056) induces shorter and more intense southern hemisphere summers (similar to Mars). Titan's atmosphere superrotates at altitude but this flow does not dominate surface wind patterns. Near-surface circulation on Titan is dominated by solar heating that induces Hadley cell formation, with the winds generated by the return flow of each cell. The cells rise either side of the ITCZ (Flasar et al. 2010) and extend to high latitudes. At each solstice a single Hadley cell rises in the high latitudes in the summer hemisphere and sinks at the winter pole. These produce northerly surface winds during the southern summer and southerly winds during the northern summer. The Coriolis force causes westerly components in the mid-latitudes and an easterly deflection close to the equator. A modelled strong westerly $1-1.5 \mathrm{~ms}^{-1}$ at the equinoxes may orient the linear equatorial dunefields (Tokano 2010).

\subsubsection{Venus}

The atmosphere on Venus is the densest of the four bodies (Table 11.1). As a consequence, an extreme greenhouse effect traps heat and reduces spatial and temporal surface temperature variability. Hadley cell circulation rises at the equator and descends at the poles, with southern hemisphere winds deflected to the west by topography (as planetary rotation rate is very low (1 Venus day $=116.8$ Earth days) (Table 11.1). Global circulation is generally towards the equator. Very little data is available on the atmospheric circulation of Venus. Similar to Mars, slope winds may be important on Venus.

\subsection{Planetary Sediment Transport (Mars, Titan, Venus)}

Sediment transport is responsible for a broad range of geophysical phenomena, including dust storms on Earth and Mars and the formation and migration of dunes on both planetary bodies, as well as on Venus and Titan (Bourke et al. 2010; Kok et al. 2012). In particular, the shape and migration of dunes provide excellent proxies for the characteristics of sediment transport across the surface of planetary bodies (Lorenz and Zimbelman 2014). This section aims briefly to discuss these characteristics, as well as presenting open questions on planetary sediment transport that need to be addressed to improve our understanding of planetary geomorphology, with emphasis on dune formation and migration.

Indeed, there are important differences in the scale and dynamics between dunes on Earth and their extra-terrestrial counterparts. A considerable body of research in the last two decades has been devoted to the understanding of these differences. This has helped us to identify characteristics of sediment transport that are particular to each distinct physical environment, and has pushed forward our understanding of the sediment transport on our own planet (Kok et al. 2012).

As discussed in Chapter 2, the transport of sediments along the surface occurs mainly through saltation, which starts when the wind shear velocity $u_{*}$ exceeds a minimal threshold $u^{\prime \prime f t}$ - called the fluid threshold for initiating transport (Bagnold 1941; Iverson and White 1982). Once transport begins, particles move in nearly ballistic trajectories close to the ground thereby ejecting new particles upon collisions with the bed (splash). Because of the contribution of splash to grain entrainment, saltation can be sustained at a wind velocity that is less than the one required to lift sand grains. The associated threshold shear velocity is 
called the impact threshold $u_{* t}$, which for aeolian transport on Earth is about $80 \%$ of $u_{* \mathrm{ft}}$. However, the relation between $u_{* \mathrm{t}}$ and $u_{* \mathrm{ft}}$ is not the same for Earth, Mars, Venus, and Titan, as the characteristics of sediment transport differ substantially among the four planetary bodies as shown in Table 11.2.

\subsubsection{Mars}

Because the atmosphere of Mars is thin (nearly 80 times less dense than the Earth's), sediment transport begins at wind speeds one order of magnitude larger than those required to entrain sand on Earth. The higher entrainment wind speeds, the lower gravity, and thinner atmosphere of Mars lead to much longer and higher saltation trajectories than those of terrestrial sand grains (see Table 11.2). A critical consequence of the larger saltation trajectories on Mars is that Martian grains hit the surface with much higher energy than saltating particles on Earth, which causes the efficiency of the splash in ejecting grains from the surface on Mars to be higher than on Earth (Marshall and Stratton 1999; Parteli and Herrmann 2007).

The puzzle is this: wind shear velocity values on Mars estimated from in situ measurements of the wind velocity profile by Martian Landers are typically below $1.0 \mathrm{~m} \mathrm{~s}^{-1}$, which equates to estimated average values of $u_{*}$ on Mars in the range between 0.3 and $0.6 \mathrm{~m} \mathrm{~s}^{-1}$ (Sutton et al. 1978; Sullivan et al. 2000; Holstein-Rathlou et al. 2010). Yet such values are well below the fluid threshold $u_{* \mathrm{ft}}$ on Mars (see Table 11.2). That sediment moved at all on Mars was intriguing.

Observations by early missions to Mars provided only occasional evidence for aeolian surface changes on loose surfaces on Mars (Kok et al. 2012). In particular, the first in situ evidence for aeolian transport on the surface of an extraterrestrial planet was registered only after the third winter of the Viking 1 mission, that is, after 2.5 Martian years or five Earth years of mission observations. Arvidson et al. (1983) reported enthusiastically:

(...) The movement of the rock, the alternations of the conical piles, clods, trenches, and other features, and the increase in scene contrast, demonstrate that an erosion event or events of substantial magnitude occurred during the third winter season, probably between Sols 1720 and 1757.

In fact, in sol 1742 (a mean Martian solar day, or 'sol', is about 24 hours, 39 minutes and 35.244 seconds), an image was acquired, that showed an enormous storm in progress, which has been named 'The Martian Dust Storm of Sol 1742' (Moore 1985). The changes in the surface during that event included significant erosion of sand piles constructed by the lander at the landing site and the formation of a ripple-like bed with wavelengths of several centimetres (Arvidson et al. 1983). Thus, the bed modifications represented the first evidence that saltation could occur under present atmospheric condition of Mars.

In the three subsequent decades, the general view of Martian aeolian processes was that saltation transport occurs in short gusts of strong (but rare) aeolian activity (Sullivan et al. 2005; Parteli and Herrmann 2007; Almeida et al. 2008).

However, advances in image modelling and processing, made in the last decade, have permitted the measurement of relative displacements between images to the sub-pixel level, and led to a revolution in our knowledge of Martian dune dynamics (Bridges et al. 2012b; Silvestro et al. 2013; Ayoub et al. 2014). In particular, the migration of dunes and ripples on Mars has been found to be ubiquitous: large sand dunes migrate at several centimetres a year (Bridges et al. 2012a). Such high migration rates come as a surprise considering that the fluid threshold shear velocities on Mars are much larger than the average wind shear velocities on the Red Planet (Kok et al. 2012). 
Table 11.2 Characteristics of saltation transport on Earth, Mars, Venus, and Titan.

\begin{tabular}{|c|c|c|c|c|c|c|c|c|c|}
\hline $\begin{array}{l}\text { Planetary } \\
\text { body }\end{array}$ & $\begin{array}{l}\text { Gravity (g) } \\
\left(\mathrm{m} \mathrm{s}^{-2}\right)\end{array}$ & $\begin{array}{l}\text { Air density } \\
\left(\mathrm{kg} \mathrm{m}^{-3}\right)\end{array}$ & $\begin{array}{l}\text { Particle density } \\
\left(\mathrm{kg} \mathrm{m}^{-3}\right)\end{array}$ & $\begin{array}{l}\text { Typical particle } \\
\text { size }(\mu \mathrm{m})\end{array}$ & $\begin{array}{l}\text { Fluid threshold } u_{* \mathrm{ft}} \\
\left(\mathrm{m} \mathrm{s}^{-1}\right)^{a}\end{array}$ & $\begin{array}{l}\text { Ratio of impact to fluid } \\
\text { threshold, } u_{*_{t}} / u_{* \mathrm{ft}} b\end{array}$ & $\begin{array}{l}\text { Typical saltation } \\
\text { height }(\mathrm{cm})^{b}\end{array}$ & $\begin{array}{l}\text { Typical saltation } \\
\text { length }(\mathrm{cm})^{b}\end{array}$ & $\begin{array}{l}\text { Dune scale } \\
\text { (m) }\end{array}$ \\
\hline Earth & 9.81 & 1.2 & 2650 & $150-250$ & $\sim 0.2$ & $\sim 0.8$ & $\sim 3$ & $\sim 30$ & $5-10$ \\
\hline Mars & 3.71 & 0.02 & 3000 & $100-500$ & $\sim 1.5$ & $\sim 0.1$ & $\sim 10$ & $\sim 100$ & $\sim 100$ \\
\hline Venus & 8.87 & 66 & 3000 & Unknown & $\sim 0.02$ & $>1$ & $\sim 0.2$ & $\sim 1$ & $0.1-0.3$ \\
\hline Titan & 1.352 & 5.1 & 1000 & Unknown & $\sim 0.04$ & $>1$ & $\sim 0.8$ & $\sim 8$ & $1-2$ \\
\hline
\end{tabular}

$a^{a}$ computed with the equations of Iversen and White (1982).

${ }^{b}$ obtained from numerical simulations by Kok et al. (2012). 
The puzzle has been somewhat resolved by computer simulations (Almeida et al. 2008; Kok 2010a) that demonstrated the effect of the Martian splash. Subsequent entrainment of saltating particles could cause the ratio $u_{* \mathrm{t}} / u_{* \mathrm{ft}}$ on Mars to be substantially lower than on Earth. Values of this ratio as small as $10 \%$ have been predicted, which means that sand transport on Mars might ensue even if the wind strength decreases down to Earth-like values. Although there is little evidence for a lower $u_{* \mathrm{t}} / u_{* \mathrm{ft}}$ on Mars than the corresponding value on Earth (Ayoub et al. 2014), this difference could be the explanation.

The new picture of Martian sediment transport proposed by Almeida et al. (2008) and Kok (2010b) offers an explanation for such sand fluxes in spite of the high Martian threshold for aerodynamic entrainment. Specifically, a plausible explanation for the Earth-like fluxes on Mars is the low Martian impact threshold $u_{*}$, which allows sand to be transported at normal Martian wind speeds (Almeida et al. 2008; Kok 2010a). This explanation still needs to be supported by wind tunnel measurements that confirm the predicted value of $u_{* *}$. Nevertheless there are deeper consequences for a broad range of aeolian processes on the surface of the Red Planet.

Much progress has been achieved in the development of reliable theoretical expressions for computing the saturation length $L_{\text {sat }}$, and saturated flux, $Q$, of sediment transport as a function of flow conditions and the attributes of sediment and fluid. By estimating these quantities from the size and migration speed of planetary dunes, valuable information can be gained indirectly about grain size, wind velocity and duration of the sand moving wind gusts on planetary surfaces (Kok et al. 2012; Pähtz et al. 2013).

\subsubsection{Venus and Titan}

As shown in Table 11.2, the threshold shear velocities for direct entrainment on Venus and Titan differ from those on Mars, and are an order of magnitude smaller than on Earth.
The much lower wind speeds required to mobilise sand grains and the large atmospheric density relative to the Earth's lead to smaller saltation trajectories, with particles jumping to heights lower than about a centimetre. Moreover, the lower trajectories mean that particles acquire low downwind velocities, which substantially decreases the strength of their impact on the surface. In other words, the splash on Venus and Titan is of negligible importance in sand entrainment compared to the direct entrainment processes by aerodynamic forces. Therefore, saltation on Venus and Titan is probably much more akin to saltation under water, and cannot be sustained below the threshold for aerodynamic entrainment $u_{* \text { ft }}$ (Kok et al. 2012). The difference in the modes of sediment transport on Venus and Titan also have important consequences for determining the scale of dunes on these planetary bodies, as discussed below.

\subsection{From Sediment Transport to Aeolian Bedforms}

Much of our knowledge about sand flux, wind regimes, and attributes of sediment in Martian dune fields has been gained from the study of dynamics and scale of ripples and dunes detected from satellite coverage.

The main characteristics of the mechanism leading to dune formation are depicted in Figure 11.1. A topographic feature is an obstacle in the wind, which causes a reduction in the wind velocity at its upwind front and an upward deflection of the flow. At the crest, a negative pressure perturbation keeps the flow attached to the surface. This leads to a compression of the flow streamlines and thus to a higher velocity gradient (and consequently a larger shear velocity) near the crest than in the adjacent lower topography. However, the position of maximum shear velocity is not at the crest. The upward deflection of the flow at the windward side is 
Figure 11.1 Streamlines of wind flow over a hill of Gaussian profile in the along-wind direction (solid surface). $L_{\text {sat }}$ gives the spatial lag between the positions of maximal shear stress $\left(\tau_{\max }\right)$ and maximal flux $\left(q_{\max }\right)$.

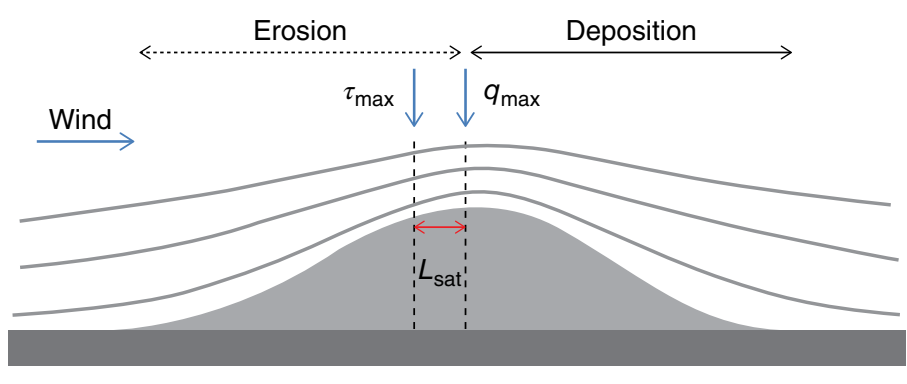

counteracted by the inertia of the turbulent velocity fluctuations at the downwind side of the hill, such that the maximal shear velocity at the surface is shifted upwind with respect to the profile of the terrain (Kroy et al. 2002; Claudin et al. 2013). That is, if the sand flux responded with no delay to wind velocity, the maximum flux would always occur upwind of the crest, and thus sand would be always deposited on the bump thus leading to dune growth.

However, there is a finite time (or equivalently a saturation length, $L_{\mathrm{sat}}$ ) for the sand flux to react to a change in flow conditions. The bump grows and evolves into a dune only if its size is large enough such that the flux is maximal upwind of the bump's crest. In other words, the saturation length defines a minimal length scale below which the bump is eroded and a dune cannot form (Kroy et al. 2002). Based on empirical observations of the minimal dune size in air and under water, the following approximate relation has been proposed (Hersen et al. 2002):

$$
L_{\text {sat }} \approx 2 d \rho_{\text {grain }} / \rho_{\text {fluid }}
$$

where $d$ is the average particle diameter, $\rho_{\text {fluid }}$ is the fluid density and $\rho_{\text {grain }}$ is the particle density. This scaling relation has been improved by a theoretical model for $L_{\text {sat }}$ (Pähtz et al. 2013), which further reproduces the dependence of $L_{\text {sat }}$ on $u_{*}$ observed for sediment transport in the subaqueous regime (which dictates dune formation on Venus and Titan) and is consistent with measurements of the saturation length over at least 5 orders of magnitude in the ratio of fluid and particle density (Figure 11.2).
Ripples are smaller than $L_{\text {sat }}$. The origin of ripple formation is a 'screening' instability of the sand surface exposed to the impact of saltating particles (Anderson 1987; Fourrière et al. 2010). Saltating grains colliding obliquely onto a sand bed eject many reptating grains (see Chapter 2), thereby generating small depressions on the surface and leading to a chain of small-scale undulations of asymmetric profile. The windward side of the perturbations is less steep than the lee side, and is the side most exposed to impacts of the saltating particles. In contrast, the lee side is less susceptible to erosion by grain impact such that reptating grains falling in the lee accumulate there, thus leading to ripple growth. While dune migration velocity gives a proxy for saltation flux, ripple migration rates are controlled by the flux of reptating particles.

\subsubsection{Deriving Sediment Transport Characteristics from Planetary Bedform Characteristics}

The main quantities controlling the characteristics of sediment transport, that is the steady-state flux (or saturated flux; see Chapter 2) and the saturation length, can be obtained indirectly from the dynamics and scale of planetary dunes.

Specifically, the saturated (bulk) flux $Q$ (in units of area per unit time) can be obtained by measuring the displacements of planetary barchan dunes. Indeed, the migration velocity of a barchan can be estimated for a dune in steady state by applying mass conservation at the dune's crest (Bagnold 1941 ), which yields a scaling of $v_{\mathrm{m}} \approx a Q / W$, 


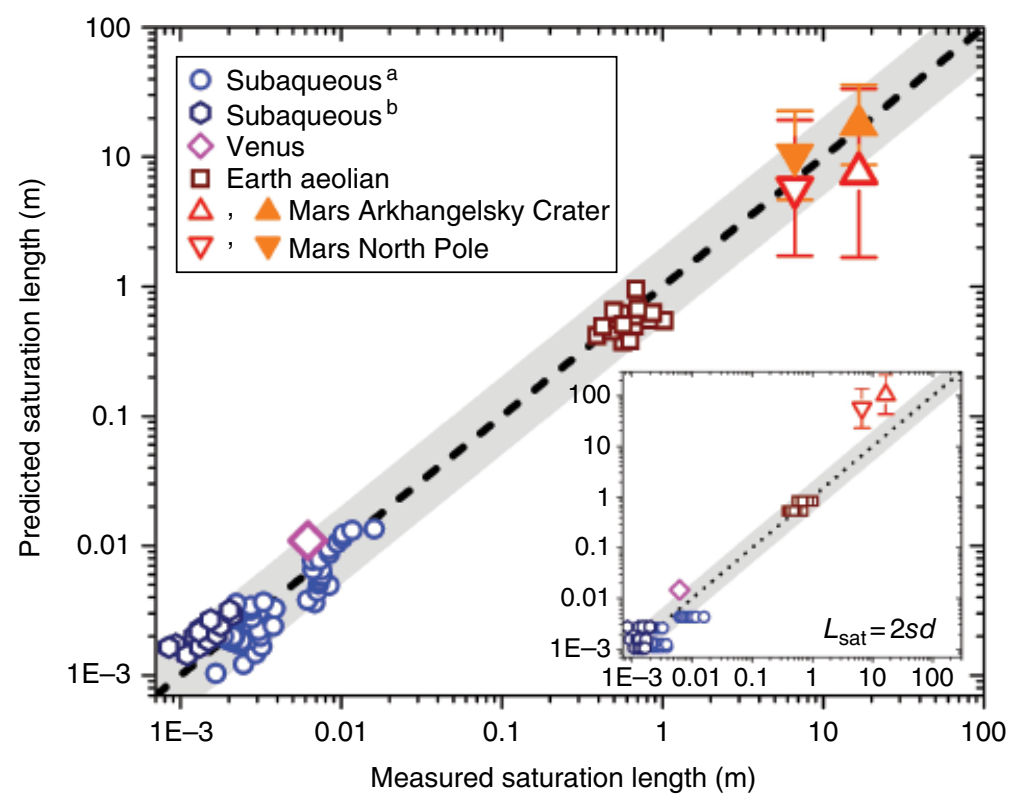

Figure 11.2 Values of $L_{\text {sat }}$ estimated from measurements and predicted from theory (Pähtz et al. 2013). Measurements of $L_{\text {sat }}$ for subaqueous sediment transport were based on experimental data of Fourrière et al. (2010) and Franklin and Charru (2011) (data sets ' $a$ ' and ' $b$ ', respectively). For Venus, $L_{\text {sat }}$ was estimated from the crest-to-crest distance of elementary dunes (Greeley et al. 1992). Field and wind-tunnel measurements of $L_{\text {sat }}$ for aeolian transport on Earth were provided by Andreotti et al. (2010). For Mars, $L_{\text {sat }}$ was derived from the minimal size of barchans (Lorenz and Zimbelman 2014; Parteli et al. 2007), and plotted against $L_{\text {sat }}$ predicted using average particle size $d=100-600 \mu \mathrm{m}$ (Bourke et al. 2010). The filled symbols use $u_{*}=u_{* f t}$, while the open symbols use $u_{*}$ obtained from Viking 2 wind speed measurements using a theoretical model (Pähtz et al. 2013). The inset shows measured and predicted values of $L_{\text {sat }}$ for the same conditions as in the main plot, but using a different model proposed by Claudin and Andreotti (2006). According to this model, $L_{\text {sat }}=2 s d$, where $s$ is the grain to fluid density ratio. Source: After Pähtz et al. (2013).

where $a \approx 50$ (Durán et al. 2010), and, equivalently, an approximate scaling of $v_{\mathrm{m}}$ with $\mathrm{Q} / H$, with $H$ standing for the dune height. Therefore, the saturated flux follows the scaling $\mathrm{Q} \sim H D / T$, where $D$ is the distance covered by a barchan within the observation time span $T$ (Bridges et al. 2012b). Note that $Q$ is related to the average, height-integrated steady-state mass flux $q$ of transported particles, in units of mass per unit length and per unit time, through the equation $Q=q / \rho_{\text {bed }}$, where $\rho_{\text {bed }}$ is the average density of the sediment bulk, which for loose sand is typically around $62 \%$ of $\rho_{\text {grain }}$ (Bagnold 1941; Durán et al. 2010; Kok et al. 2012).

The saturation length $L_{\text {sat }}$ can also be estimated indirectly from the minimal crosswind width $W$ of barchan dunes through the approximate relation $W \approx 12 L_{\text {sat }}$ (Parteli et al. 2007). Barchans smaller than the minimal size do not display limbs or a slip face and have a dome-like shape. The largest dome which has neither slip face nor limbs and is smaller than the smallest barchan dune indicates the minimal dune size. This method has been used to estimate values of $L_{\text {sat }}$ in different dune fields on Mars from the scale of barchan dunes (Parteli and Herrmann 2007), and the values obtained by this method were reproduced by theoretical calculations adopting plausible grain sizes and average wind shear velocities valid for Mars (Pähtz et al. 2013).

Yet another method of estimating $L_{\text {sat }}$ is based on a theoretical model which relates the saturation length to the wavelength or 
crest-to-crest distance of 'elementary dunes', i.e. the smallest superimposed dunes occurring on a flat surface or on top of large barchan dunes (Andreotti et al. 2010; Fourrière et al. 2010). This method was used to obtain $L_{\text {sat }}$ from the crest-to-crest distance of Venusian microdunes $(10-30 \mathrm{~cm})$ produced in wind tunnel experiments under atmospheric conditions valid for Venus (Greeley et al. 1992). Finally, by computing $L_{\text {sat }}$ under atmospheric conditions valid for Titan, the predicted wavelength of elementary dunes on Titan is about $1.5 \mathrm{~m}$ (Claudin and Andreotti 2006), which, unfortunately, is well below the resolution of Cassini's radar.

\subsection{Planetary Aeolian Deposition Features: Dunes, Sand Seas, Sediment Source}

\subsubsection{Mars}

The geomorphic processes that generate sediment for aeolian entrainment have changed through time on Mars. Early in Mars's history (the Noachian and Hesperian: 4.1-3.0 Ga) surface processes were dominated by impact-cratering processes that broke apart the primordial crust to form a megaregolith (a range of grain sizes from megaclasts to silt and clay). It was also a time of extensive volcanic activity and a period where a thicker atmosphere permitted a phase of chemical weathering (leading to extensive deposits of clay minerals), active fluvial processes, catastrophic flooding, and the formation of lakes and potentially an ocean. It was also a time of aeolian activity.

Stratigraphic evidence exposed in the walls of small craters suggests that the history of windblown dune sediment is long on Mars. The Opportunity Rover imaged thick sequences of aeolian cross-bedded sandstone that probably date back $3.5 \mathrm{Ga}$ (Grotzinger et al. 2005). These are the oldest known aeolian sandstones in our solar system.

We know, from several decades of surface and orbiting observations, that Mars's surface displays aeolian dune forms with a wide range of sizes and morphologies (typically transverse). Other, smaller aeolian bedforms, such as ripple-like features, have now been observed by various Rover missions (Greeley et al. 2004).

There are approximately 2000 dunefields on Mars that cover an area of $\sim 904000 \mathrm{~km}^{2}$ (Hayward et al. 2007; Fenton and Hayward 2010). The majority of these dunes are located in large dunefields that circle the North Polar ice cap. The remainder of the dunefields are located in topographic traps on the floor of impact craters and intercrater plains. The dunefields are found both in the deepest topographic lows on Mars (e.g. Hellas basin $-7 \mathrm{~km}$ ) and at elevations of $10-21 \mathrm{~km}$ above datum.

The lithology of the majority of grains on Mars is basalt. Grain density is $3.0 \mathrm{~g} \mathrm{~cm}^{-3}$ as compared to quartz $\left(2.65 \mathrm{~g} \mathrm{~cm}^{-3}\right)$. Dunes may contain some more locally-derived minerals. For example, dunes in the Olympiae Undae have gypsum concentrations that may be ablated from the polar cap (Massé et al. 2010).

Many of the modern extensive dune fields have local sediment sources. The North Polar dunefields sediment is likely sourced from the adjacent polar layered deposits (Edgett et al. 2003). The sources of several southern hemisphere dunefields are thought to be locally derived from exposures of sand sources in crater walls and pits in the crater floor (Tirsch et al. 2011).

Data from space-borne platforms at Mars suggest that the grain size of dune sand is medium- to coarse-grained sand (Edgett and Christensen 1991). Lander and Rover platforms suggest finer sand with sizes of 200-300 $\mu \mathrm{m}$ sand (Sullivan et al. 2008). Sites that may contain sand-sized aggregates of dust arranged in $5-30 \mathrm{~m}$ wide reticulate bedforms (Bridges et al. 2010) have also been identified. The NASA Mars Exploration Rovers examined several ripple-like landforms, each a few metres long and $5-10 \mathrm{~cm}$ or so in height, and were able to examine their interiors by 'trenching' through them with their wheels. They found that although 


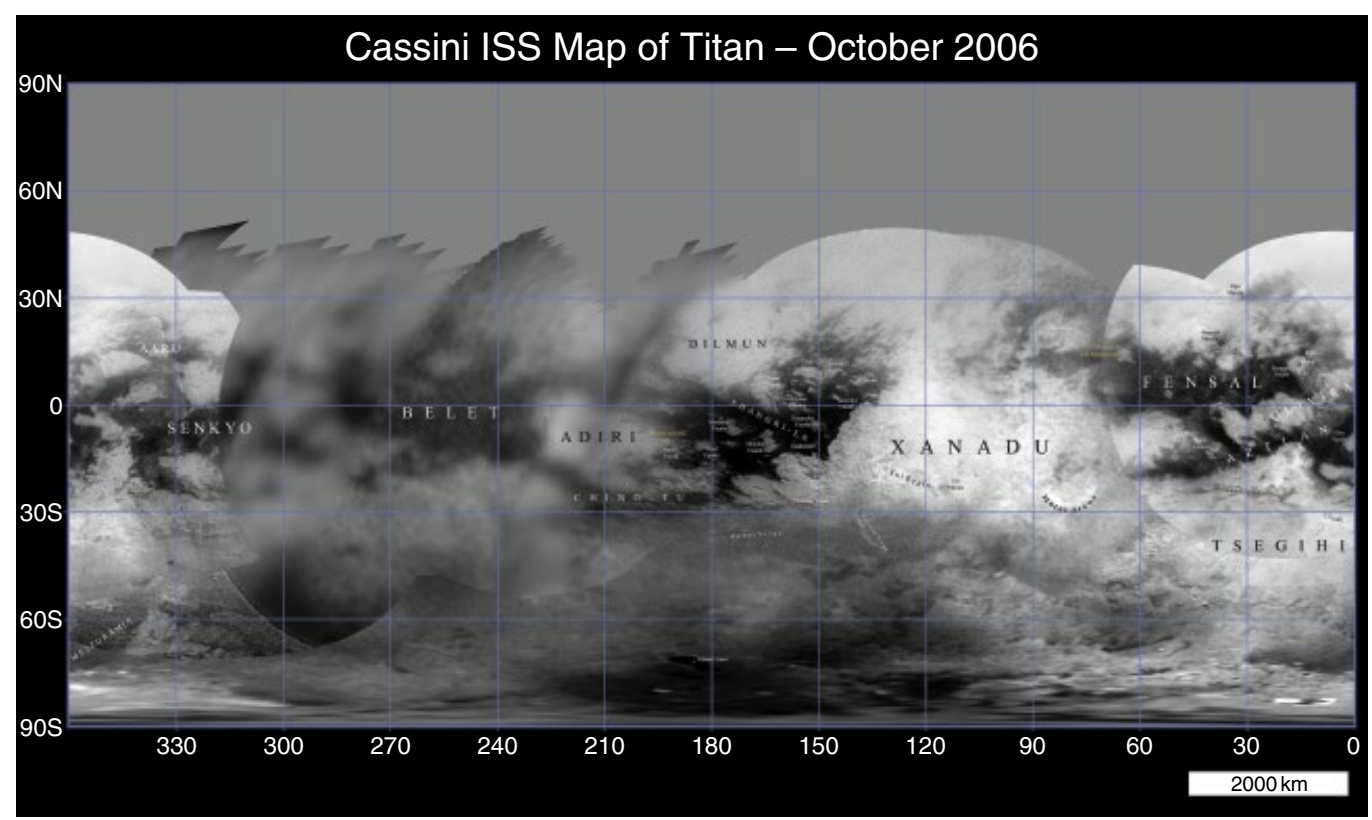

Figure 11.3 A near-infrared map of Titan, showing major named bright and dark regions around the equator: the dark regions are sand seas.

their surfaces were covered by sand and sometimes granule-sized grains, their interiors included many grains too small to be resolved by the microscopic imager $(<30 \mu \mathrm{m}$ in diameter) as well as $\sim 50-100 \mu \mathrm{m}$ diameter fine sand-sized material (Sullivan et al. 2005).

\subsubsection{Titan}

The likelihood of dunes on Titan was noted, as soon as it was determined by the Voyager 1 encounter in 1980 that it had a thick atmosphere (Greeley and Iversen 1985). But while a dense atmosphere and low gravity mean the wind speed threshold to move particles is small, it also means that the solar-driven buoyant forces lead to proportionately weak winds. The expectation of hydrocarbon seas on Titan also conditioned expectations, since such seas might act as sand traps. However, these cautions were confounded by Titan's diversity (Lorenz et al. 1995). Because Titan rotates slowly, its Hadley circulation is more extensive and its lower latitudes become desiccated and methane moisture is transported to the North Pole. It turned out that the dark regions girding Titan's equator (Figure 11.3) are vast seas of giant linear dunes, covering some $\sim 15 \%$ of Titan's surface (Lorenz et al. 2006). A couple of low, dark dunes are visible in the mosaic of images made by the Huygens probe during its parachute descent in 2005, but the principal means of surveying Titan's dunes has been the Cassini radar mapper.

The dunes appear (Figure 11.4) to have a morphology and size very similar to those of the largest linear dunes on Earth, in the Namib and Arabian deserts, with spacing of around $3 \mathrm{~km}$ and lengths of tens to hundreds of $\mathrm{km}$ (Radebaugh et al. 2010). The dune heights have been inferred from radar measurements to be up to about $150 \mathrm{~m}$. Despite Titan's atmosphere being dense, its gravity being $1.35 \mathrm{~ms}^{-2}$ (like the Earth's moon) and the particle composition being very different from Earth, it seems that the controlling parameter on the scale of mature dunes (Andreotti et al. 2009) is the thickness of the atmospheric boundary layer, which is about $3 \mathrm{~km}$ on both Titan and Earth (Lorenz et al. 2010), Titan's denser atmosphere is compensated for by its longer day-night cycle. 
Figure 11.4 A Cassini radar image (about $100 \times 300 \mathrm{~km}$ ) of the Belet sand sea on Titan. The linear features are sand dunes - in other places simply as dark streaks, but here with bright glints on their north flanks (the radar illumination is from the north/ above) indicating their positive relief of about $100 \mathrm{~m}$.

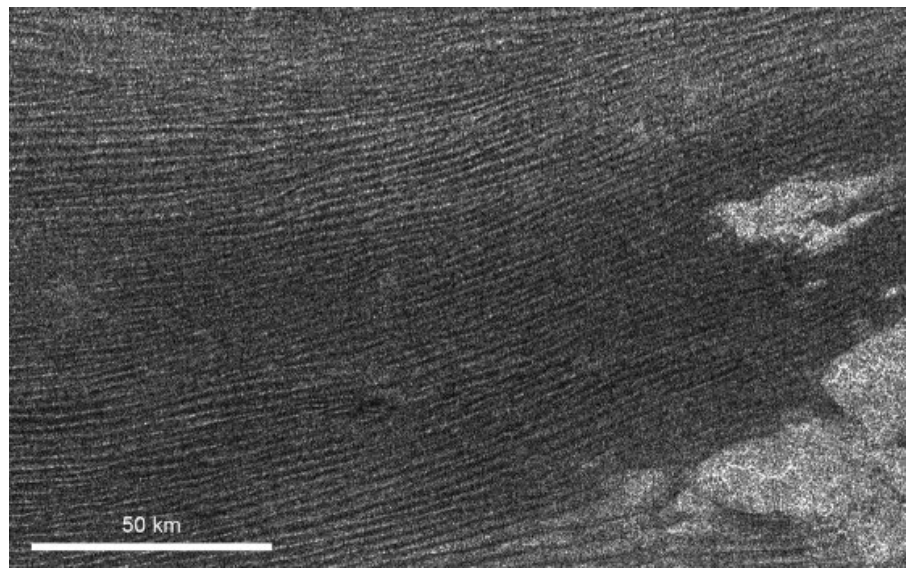

Although there may be a few barelyresolved hooked barchans, and a few transverse dunes where topographic barriers 'straighten' seasonally-varying winds, the dominance of linear dunes on Titan (e.g. Lorenz et al. 2006) attests to a bidirectional wind regime (Chapter 6; see also Reffet et al. 2010). This regime was first thought to be caused by atmospheric tides, but it now appears to be due to a seasonal north-south Hadley circulation (Tokano 2008). For some years atmospheric modellers struggled to explain the clearly West-East direction of dune propagation on Titan, because, for most of the year, the low-latitude winds should be blowing in an East-to-West direction. It may be that the dunes reflect only the brief but fastest winds around the stormy spring equinox, when winds are in fact West-East; another is that haboob-type outflows from methane rainstorms preferentially cause eastwards transport (Charnay et al. 2015). The topic remains an area of active research (e.g. Lucas et al. 2014). Circulation models do, at least, satisfactorily predict that a band around the equator should dry out, occasional methane rainstorms notwithstanding, which is where the dunefields are found (Mitchell 2008). The $\pm 30^{\circ}$ band of dunes makes an interesting contrast - owing mainly to Titan's slow rotation which determines the Hadley circulation - to the two latitude belts where most of the terrestrial deserts are found. The dunefields (the major ones are Belet, Shangri-La, Fensal, and Aztlan - see Figure 11.3) form a dark equatorial belt that is visible (even with the largest telescopes) from Earth. This belt is broken by a large bright and mountainous region named Xanadu - it is not yet clear whether the sand circumnavigates Titan; if so, it must somehow be transported through or around Xanadu (Barnes et al. 2015).

Titan's dunes are of an optically-dark material with a low dielectric constant, consistent with an organic composition, and an organic, possibly aromatic, character is indicated by some Cassini spectroscopic data. Thus, the sands are presumably derived ultimately from the photochemical processing of methane in the atmosphere, which also causes an organic-rich haze which makes Titan's atmosphere optically-opaque. However, the process by which $1-\mu \mathrm{m}$ aerosol particles (which may be a sticky mix of refractory organics as well as liquid ethane) become $\sim 200 \mu \mathrm{m}$ saltating particles is not known - it may be related to hydrologic erosion of massive deposits of organics, or it may be connected with climate cycles on Titan wherein the seas dry out at alternate poles over periods of tens of thousands of years. Even at Titan's low temperature of $94 \mathrm{~K}$, simple organics like benzene are white, waxy solids: a more complex composition appears to be needed, perhaps polycyclic 
aromatic hydrocarbons (PAHs), such as pyrene and anthracene, or even some nitrogencontaining versions of these. There is at present relatively little understanding of the behaviour of such materials in saltation in Titan's conditions - would sand made of such material be rapidly ground into dust?

Assuming that Titan sands are not appreciably stickier than terrestrial sands, the optimum in the saltation curve (see Lorenz et al. 2014) should correspond roughly to $1 \mathrm{~ms}^{-1}$ windspeeds and particle sizes of 200$300 \mu \mathrm{m}$, i.e. not too different from terrestrial sand. Some recent wind tunnel measurements suggest saltation thresholds may be somewhat higher, $2-3 \mathrm{~ms}^{-1}$. Such wind speeds are rather larger than those measured at the surface by the Huygens probe $\left(\sim 0.3 \mathrm{~m} \mathrm{~s}^{-1}\right)$ but models predict that such winds - also strong enough to generate waves on Titan's hydrocarbon seas - may occur in polar summer or equatorial equinox, and storm winds (Charnay et al. 2015) especially can exceed this (Burr et al. 2015).

\subsubsection{Venus}

Although Venus's thick atmosphere should make aeolian sediment transport relatively easy, near-surface winds may be somewhat gentle. However, a more important consideration may be the limited availability of sediment: there are no freeze-thaw cycles to generate sediment, nor is there a (hydrological) cycle, such as the methane cycle on Titan. Thus, the main source of sand-sized sediment may be ejecta from impact craters and there do appear to be some streaks of material associated with small volcanoes (Greeley et al. 1992).

The Magellan mission which mapped Venus in the early 1990s had a best radar resolution of only $\sim 100 \mathrm{~m}$, so only the largest dune features are visible. They form two dune fields, Algaonice and FortunaMeshkenet (Greeley et al. 1992). There may be rather widespread 'microdunes' suggested by wind tunnel experiments under Venus

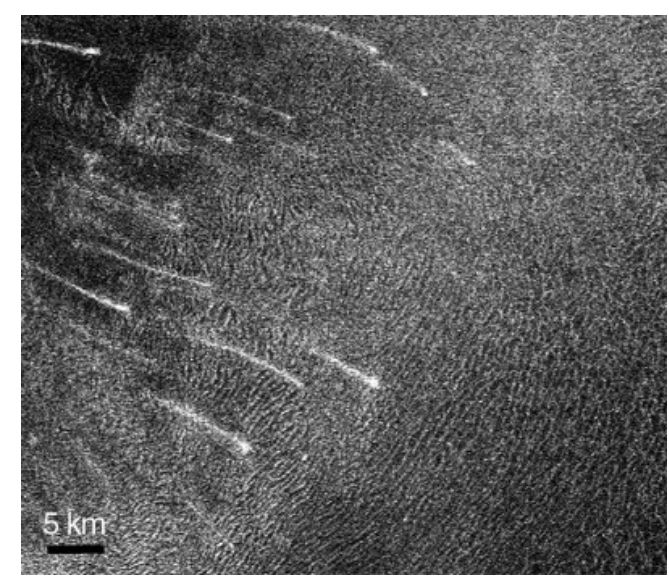

Figure 11.5 Magellan radar mosaic of the Fortuna-Mesknet dunefield on Venus. These dunes appear to be rather more extensive than the Algaonice dunes. Like the Algaonice, these dunes appear to be transverse, orthogonal to the prominent windstreaks.

conditions which show bedforms with slip-faces, but with spacings of only a few tens of centimetres, detectable indirectly. Future missions, with instruments that have higher resolution, may reveal more abundant dune forms.

The Algaonice dunes (also known as Menat Undae) on Venus at $25^{\circ} \mathrm{S}, 340^{\circ} \mathrm{E}$ cover some $1300 \mathrm{~km}^{2}$, are $0.5-5 \mathrm{~km}$ in length, and are quite bright, likely because there are slip faces of $\sim 30^{\circ}$ oriented towards the radar illumination. The dunes lie at the end of the ejecta outflow channel from the Algaonice impact crater of that name, but because the dunes are only barely resolved, there is little more information.

A more northern dunefield, FortunaMeshkenet (also known as Al-Uzza Undae), lies at $67^{\circ} \mathrm{N}, 91^{\circ} \mathrm{E}$ in a valley between Ishtar Terra and Meshkenet Tessera. The dunes are $0.5-10 \mathrm{~km}$ long, $0.2-0.5 \mathrm{~km}$ wide and spaced by an average of $0.5 \mathrm{~km}$. They appear (see Figure 11.5) to be transverse dunes, in that there are several bright wind streaks visible in the region, which seem generally to be orthogonal to the dunes (Greeley et al. 1997; Lorenz and Zimbelman 2014). 


\subsection{Aeolian Dust}

Aeolian dust is usually defined as sediment that travels in suspension in the atmosphere, rather than in saltation or as bedload (creep or reptation, see Chapter 2). Dust is therefore distinct from larger sand- and granule-sized material, but there is no specific size at which dust becomes sand; differences in particle density and shape can produce materials with transitional behaviours. In fact, on planetary bodies with different gravity and atmospheric compositions and densities, this transition between suspension and saltation can span very different size ranges. In general, though, a commonly applied distinction is that sandgrade material is $>62.5 \mu \mathrm{m}$ in diameter, with smaller particles being defined as dust. This size definition equates dust with what a sedimentologist would define as 'clay and silt. In the current terrestrial atmosphere, two populations of aeolian dust exist: fine dust $<15 \mu \mathrm{m}$ in diameter, which can remain airborne in suspension almost indefinitely, and coarse dust $>50 \mu \mathrm{m}$ in diameter, which is transported in suspension for only tens or a few hundreds of kilometres (see Chapter 4).

The dustiness of the Earth's atmosphere is, of course, not constant on short or long timescales: dust storms, lasting days or weeks, can raise local atmospheric dust concentration by orders of magnitude, and enormous dust deposits (loess), found across the globe, and sometimes hundreds of metres thick, are testament to long-duration enhancements of atmospheric dustiness in the past. For example, many of the thickest loess deposits are dated to the Pleistocene, during which there may have been long periods when the atmosphere was up to 40 times dustier than today (Taylor et al. 1993) (see Chapters 4 and 5).

Aeolian dust in a planetary context is, by definition, limited to those bodies with an atmosphere capable of transporting sediments: Earth, Mars, Venus, and Titan. Although there are observations of movement of sand-sized material on Mars, the limited in-situ and remote sensing data available for Venus and Titan means that no observations of dust lifting or deposition have been made for those bodies. Hence, the significance of dust as a geomorphic process on Venus and Titan is unknown. On Mars, though, the story is quite different, and there is extensive evidence for dust in the atmosphere, on the surface and an active exchange between the two (e.g. Read and Lewis, 2004).

\subsubsection{Dust in the Martian Atmosphere}

On Mars, dust is most clearly evident in the atmosphere (Figure 11.6). Planet-encircling dust storms, in which all or part of the surface is obscured from astronomical observation, have been recognised for more than a century, and Mars's atmosphere maintains a dusty 'haze' even in relatively clear periods. Large dust storms generally occur during the Martian southern hemisphere spring or summer. In any given Martian year there is about a one-in-three chance of a planetencircling dust storm, and about an $80 \%$ chance of regional dust storms (Zurek and Martin 1993).

Dust plays a critical role in the behaviour of the Martian atmosphere. This is because dust is crucial to an important atmospheric feedback process. When airborne dust absorbs solar and infrared radiation, it heats the atmosphere and creates temperature contrasts between different parts of the atmosphere. These contrasts create spatial differences in density, and these are linked to winds. The winds carry airborne dust and might also lift dust from the surface, which in turn changes patterns of heating in the atmosphere. This feedback is crucial to Martian climate variability (e.g. Mulholland et al. 2013). Even during relatively clear periods, normally during the northern hemisphere summer, when Mars is furthest from the Sun, the atmosphere has a significant haze of dust particles with effective radii of 


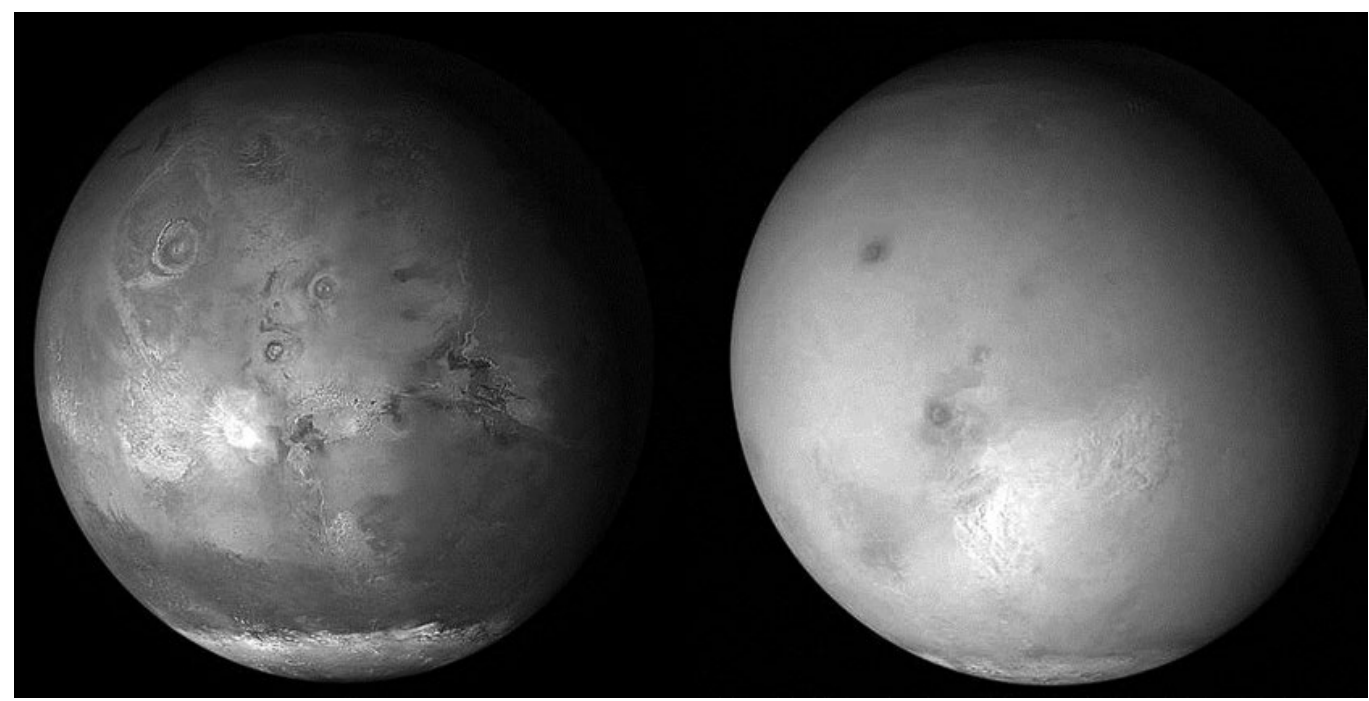

Figure 11.6 Hubble Space Telescope images of Mars taken on (left) 10 July, 2001, and (right) 31 July, 2001. The second picture shows the same hemisphere (note the circular feature that is the large volcano, Olympus Mons at upper left) as the first, but after the beginning of the great global dust storm of 2001. Source: NASA/Hubble Heritage Team.

about 1.0-1.5 $\mu \mathrm{m}$ (e.g. Wolff 2003; Wolff et al. 2006), which absorb up to $10 \%$ of the incoming sunlight. Slightly larger suspended particles have been detected during the more severe dust storms, during which more than half of the visible sunlight is absorbed in the atmosphere well above the surface. This means that less sunlight reaches the surface and so the surface becomes cooler.
Detailed models of the Martian atmosphere (Newman etal.2002) show that the background level of atmospheric dust on Mars is probably maintained by dust devils (Box 11.1). An active process is required to support the haze, because the settling rate, as measured by the appearance of calibration targets on the Mars Exploration Rovers (Kinch et al. 2007), is of the order of several $\mu \mathrm{m}$ every Martian year, so that without such a process as dust devils, the

\section{Box 11.1 Dust Devils}

Dust devils are convective vortices, powered by insolation, and made visible by the dust and debris they have entrained (Balme and Greeley 2006). They are common in arid environments on Earth, forming especially frequently during dry, hot, late summers, but have also been seen in arid polar or high elevation environments. They are mostly of the order of a metre to a few tens of metres in diameter, and tens to hundreds of metres high. Dust devils are also common on Mars, where they can be an order of magnitude larger. Dust devils on Earth are often thought to be 'nuisance-level' phenomena, but they have caused aviation accidents (Lorenz and Myers 2005) and can contribute to poor air quality (Gillette and Sinclair 1990). On Mars, though, dust devils are both agents for geomorphological change, and play a significant role in the climate, as their movement across the surface can change the surface albedo by forming extensive 'tracks', as well as being responsible for maintaining the ongoing haziness of the atmosphere (Box Figure 11.1). 
(a)

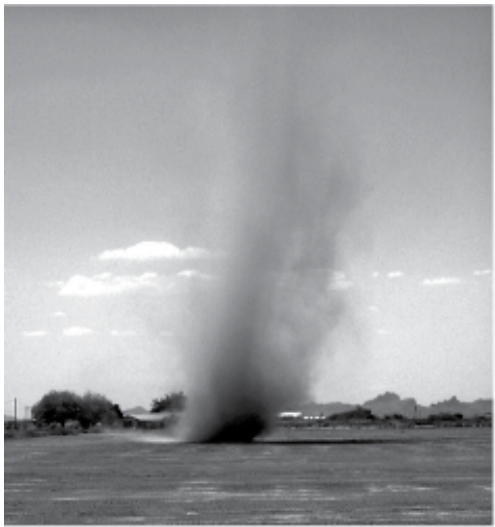

(c)

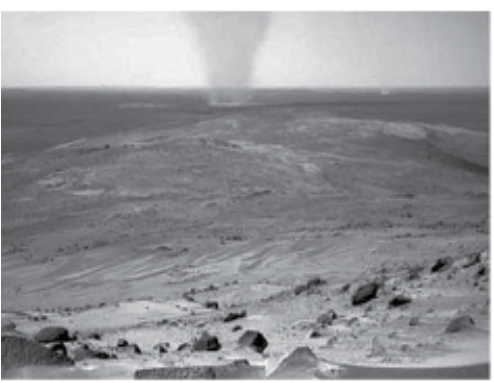

(b)

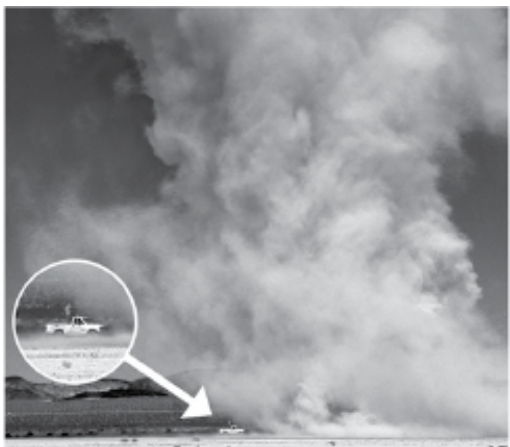

(d)

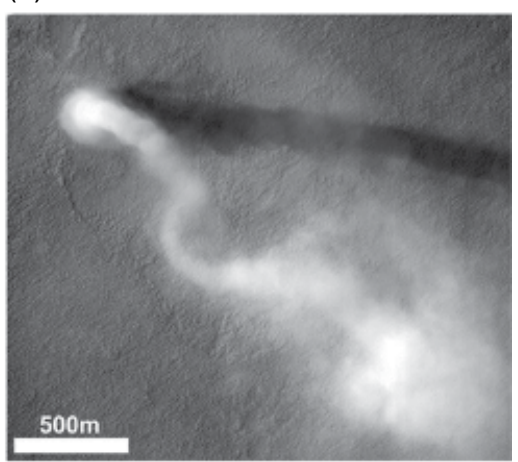

(e)

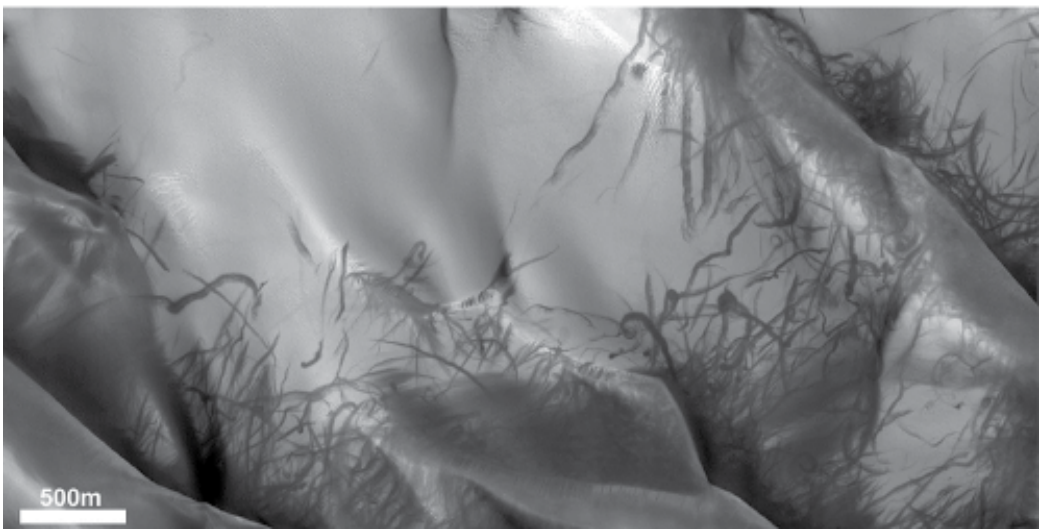

Box Figure 11.1 (a) A small ( 5m diameter) dust devil on Earth. (b) A much larger dust devil on Earth. (c) Dust devils on Mars, observed from the surface by the NASA Mars Exploration Rover 'Spirit'. (d) A large Martian dust devil observed from orbit. Note the distinctive shadow and the sinuous column. Part of HiRISE NASA image ESP_026394_2160. (e) Dust devil tracks on top of Martian sand dunes as observed from orbit. Part of NASA HiRISE image ESP_014426_2070.

atmosphere would clear more quickly between dust storms than is observed. Dust devils are most active when there is a high surface (warm) to air (cool) thermal contrast, which occurs mostly during local summer, and are suppressed when the amount of dust in the atmosphere rises (i.e. during periods with significant local, regional or global dust storms). 


\subsubsection{Sources of Martian Dust}

On Earth, dust is produced by a variety of process including comminution (the physical grinding of particles in glacial or fluvial systems), attrition (the breakdown of saltating grains), and weathering of rocks by chemical or physical means. Minor or sporadic sources include micrometeorites and volcanic ash (see Chapter 4). On Mars today there have been no observations of ongoing active volcanism and the surface is generally too cold and dry for significant fluvial or glacial processes, although limited thaw has occurred in geologically recent times (Balme et al. 2013). Hence, the production of large amounts of dust by comminution seems unlikely under present conditions. Observations of the active migration of aeolian bedforms demonstrate that saltation is occurring on Mars (Bridges et al. 2012b), so that some attrition is likely to be happening. The prevalence of dust devils and dust storms shows that dust is constantly being lifted, but it seems likely that much of this dust today is being reworked from older surface deposits, and is not being actively created in large amounts. Weathering is also likely to have been a much more significant process in Mars's ancient past than during the recent, more arid periods.

\subsubsection{Landforms Associated with Aeolian Dust on Mars}

The Mars Exploration Rovers have observed many grains too small to be resolved by the microscopic imager $(<30 \mu \mathrm{m}$ in diameter $)$ inside ripple bedforms and in dust aggregates coating rocks (Sullivan et al. 2008), leading to the inference that dust contributes to the formation of macro-forms like ripples. The small, ripple-like features observed by the various Mars Rovers transition into larger bedforms known as Transverse Aeolian Ridges (Bourke et al. 2003) that are extremely common in the Martian equatorial and mid-latitude regions (Balme et al. 2008). If these all contain significant amounts of sub-30 $\mu \mathrm{m}$ diameter materials, then globally these bedforms retain large volumes of dust. It has also been suggested that some Transverse Aeolian Ridges could be primarily formed from larger-scale loess-like dust deposits, which have been sculpted into their current ripplelike form by many thousands or millions of years of wind erosion (Geissler 2014).

As well as being present in small bedforms, dust has been a key component in the formation of global-scale Martian landscapes. For example, as first seen in Mariner 9 images, both Mars's northern and southern polar regions contain extensive layered deposits (e.g. Cutts 1973) thought to be formed of multiple horizontal to sub-horizontal alternating dark-bright layers of dust and ice (Blasius et al. 1982; Figure 11.7). It is not known whether the dark 'dust' in these layers is truly fine material, as opposed to sandgrade sediments, but their extensive nature, rhythmic layering, and topographic setting suggest that they were deposited by airfall, and so are likely to be 'dust'. The polar layered deposits are each more than a million square kilometres in spatial extent (Tanaka 2000) and are $2-3 \mathrm{~km}$ thick, so, even if they only contain a few percent of lithic material, tens of thousands of cubic kilometres of dust could be sequestered within them.

A second, dust-related landscape of global scale is the extensive blanketing terrain known as the 'latitude-dependent mantle' (LDM) (Figure 11.8). The LDM blankets the mid to high latitudes in both Martian hemispheres, and is geologically young, to judge by the paucity of superposing impact craters. The LDM is believed to comprise a mixture of dust and ice (Mustard et al. 2001; Head et al. 2003), both because it corresponds spatially to regions that have massive ground ice in their upper tens of centimetres, as measured by gamma ray spectrometry remote sensing (Feldman et al. 2004), and because it drapes the topography, and hence is likely to be of airfall origin. It covers nearly a quarter of the planet's surface and has an estimated depth of about $10 \mathrm{~m}$ (Kreslavsky and Head 2002). Although recent measurements suggest it is mainly ice $(50-95 \%$ by 
Figure 11.7 Dust/ice layering in Mars's Polar regions. This image shows a roughly east-west trending trough in the North Polar layered deposits. The dark, rough band, just below the middle of the image, is the lowest point, and contains a round structure that is an impact crater. At the top and bottom of the image are the higher edges of the trough, with layers visible in the trough walls as distinctive light and dark bands. The layers are particularly well exposed on the northern trough wall. These layers are thought to have been formed by differential erosion of variable mixtures of ice and dust. HiRISE image PSP_001462_2630. Image centred at $83.01^{\circ} \mathrm{N}, 94.82^{\circ} \mathrm{E}$. Source: NASA/JPL/UofA.
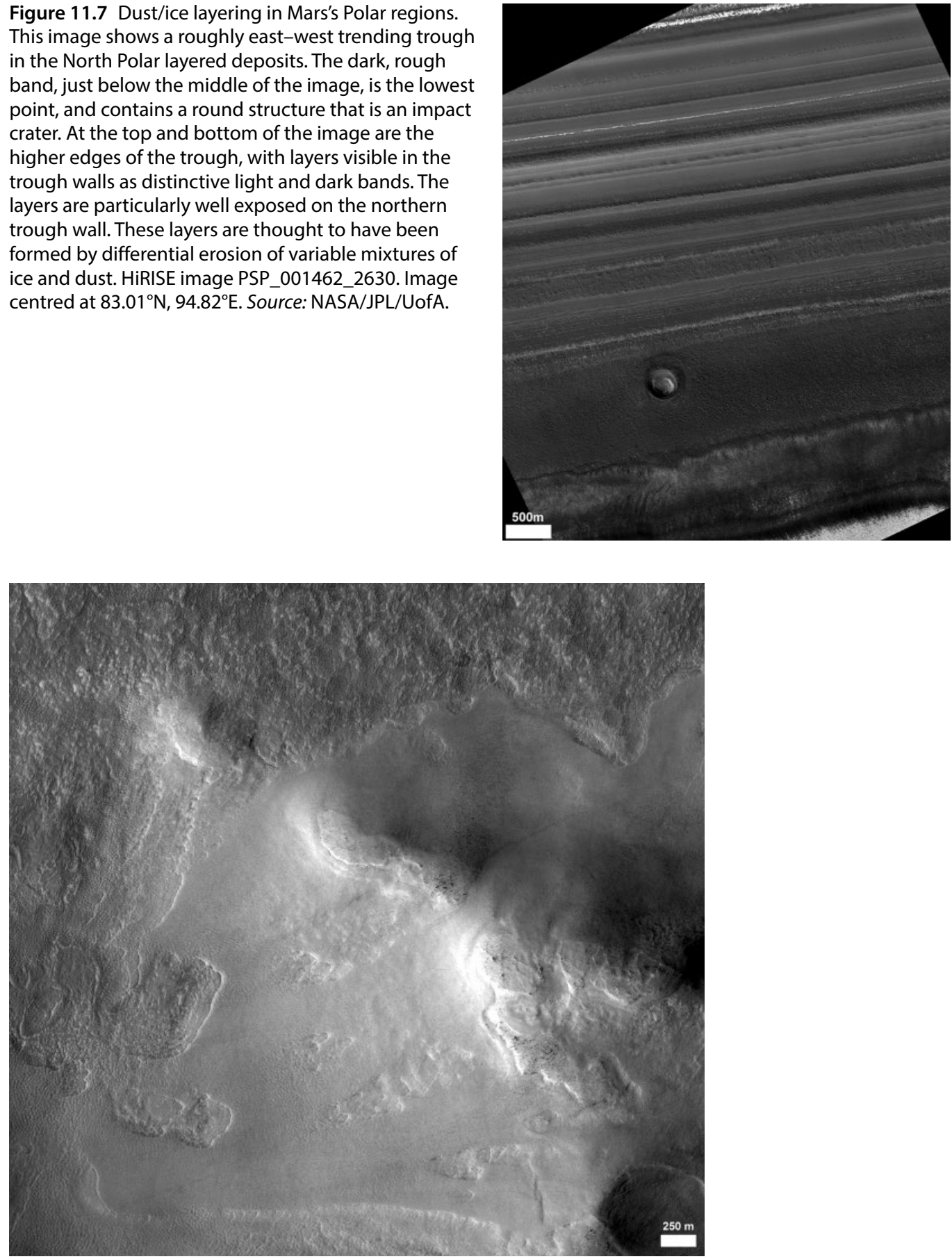

Figure 11.8 Latitude Dependent Mantle (LDM). The smoother parts of this scene are a terrain type thought to be an ice-rich, dusty 'mantle' or LDM. The lighting is from the left, revealing that the mantling material is partially 'pasted onto' the topographically higher terrain in the centre of the image, and appears to be draped over the relief in many places. Such material covers much of Mars's mid- to high-latitudes, and it is this draping property that allows the inference that the material was deposited by airfall, and hence is partly composed of dust. At the top and left of the image, the mantle is degraded, revealing the rougher, underlying surfaces. Further north (this image is at a latitude of about $50^{\circ} \mathrm{N}$ ), the mantle becomes much less degraded and is essentially continuous. Part of HiRISE image ESP_034615_231, centred at $50.769^{\circ} \mathrm{N}, 35.252^{\circ} \mathrm{E}$. North is towards the top in this image. Source: NASA/JPL/UofA. 


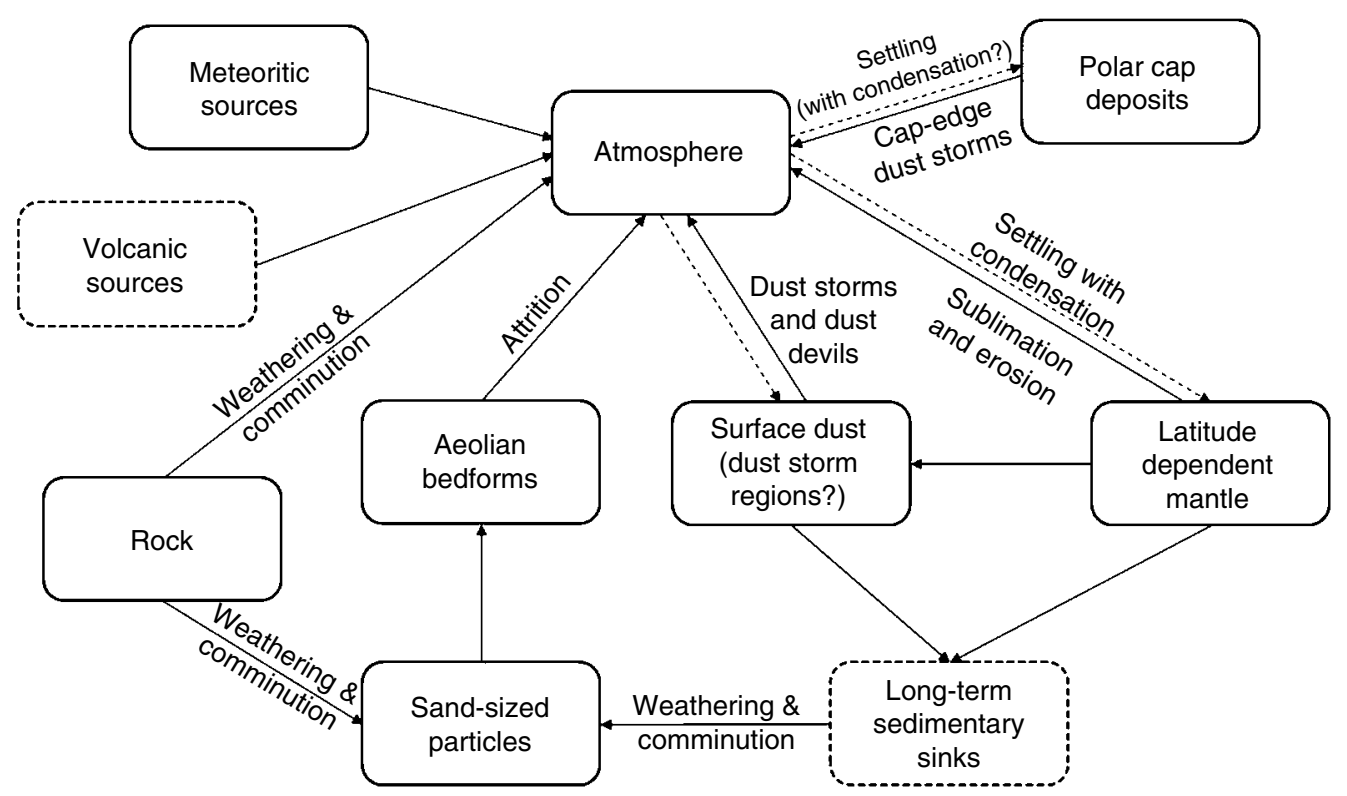

Figure 11.9 Links and feedbacks in the Martian dust cycle. Boxes represent reservoirs. Arrows indicate dust transport or formation pathway. Dashed arrows indicate gravitational settling from the atmosphere. Dashed boxes indicate sources mainly related to ancient epochs, rather than being 'active'. Source: Modified from figure in Kahn et al. (1992).

volume; Conway and Balme 2014), thousands of cubic kilometres of dust are probably contained within these deposits.

While the LDM is geologically young, having formed less than a few million years ago, traces of similar, older deposits have also been identified. Skinner and colleagues (2012) mapped extensive loess-like sediments thought to be about a billion years old. These deposits have a mean thickness of $32 \mathrm{~m}$, and extend $>3.1 \times 10^{6} \mathrm{~km}^{2}$, so they account for tens of thousands of cubic kilometres of dust, assuming that they have only a small component of ice at the present day. Importantly, Skinner and colleagues (2012) suggest that they might have been formed by the degradation or erosion of the basal components of the north polar layered deposits - presumably mediated by transport of fine grained materials and perhaps deposition into or alongside ice. This demonstrates how the complex interactions between climate change and surficial deposits of dust and ice have been ongoing throughout Mars's history and are likely still happening today.
Mars, like Earth, in its present and past, has had an active dust cycle, the intensity and character of which are controlled by climate (Figure 11.9). Sources and sinks of dust exist on Mars that are similar to those on Earth - with the main exception of the terrestrial oceans. Dust certainly plays a key role in Mars's climate, both by absorbing incoming solar radiation when airborne, and by changing the albedo and roughness of the surface as it is removed or deposited. It is unknown whether dust plays such a central role on other planets, but new highresolution imaging capabilities or new in-situ exploration missions are likely to be required before this question can be answered.

\subsection{Planetary Wind-Eroded Landforms}

In the current climate, Mars has an almost totally inactive hydrosphere, notwithstanding observations of small amounts of possible salty liquids at the surface (Ojha et al. 2015). 


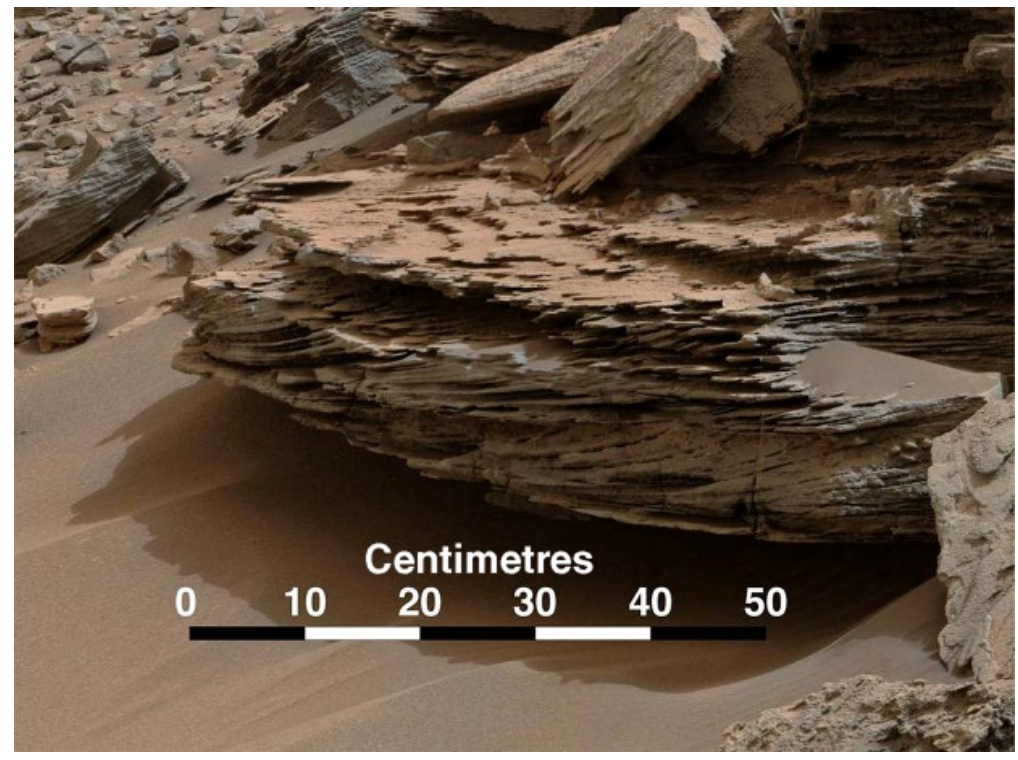

Figure 11.10 Image of etched sandstone taken by the Mastcam on the Curiosity Rover at Gale crater. Source: NASA/JPL-Caltech/MSSS.

The absence of stable liquid water results in low rates of chemical weathering (which were significant in Mars's past). The role of wind combined with sand to effect aeolian abrasion is perhaps one of the most important agents of landscape modification on Mars today. Although the Martian gravity and atmospheric density are significantly lower than Earth's (see Table 11.1), it does have: (i) a basaltic sand supply, and (ii) winds above the sediment transport threshold. Consequently, landforms that result from aeolian abrasion (ventifacts and yardangs) are observed on Mars's surface.

\subsubsection{Ventifacts}

Rocks that have been abraded by windborne particles (ventifacts, Chapter 3) are common on the Martian surface and have been observed at four Rover landing sites (Pathfinder, Spirit, Opportunity, and Curiosity) (Bridges et al. 1999; Sullivan et al. 2005; Thomson et al. 2008).

The atmospheric density and gravity on Mars suggest that abrasion will take at least 10-100 times longer than on Earth (Bridges and Laity 2013). Despite these differences, ventifact textures similar to those on Earth have been described and include facets, elongated pits, grooves, flutes, and etching (Figure 11.10).

Ventifacts provide useful proxies of former Martian sand-transporting winds where, for example, analysis of ventifacts in images taken by the Spirit Rover as it traversed the undulating terrain of the Columbia hills show the direction of funnelled winds along troughs, thus providing a useful record of past climate and landscape modification (Thomson et al. 2008).

\subsubsection{Yardangs}

Yardangs were first identified on Mars during the Mariner 9 flyby (McCauley, 1973). The later Mars Orbiter Camera (MOC) camera on the Mars Global Surveyor Mission revealed a significant surface area displaying extensively eroded sedimentary rock (yardangs, Chapter 3). The most highly concentrated distribution is in the ash/ignimbrite Medussa Fossae formation (MFF) (see example in Figure 11.11) where yardangs occur as extensive fields, some with areas of up to $40000 \mathrm{~km}^{2}$ (Mandt et al. 2008). 


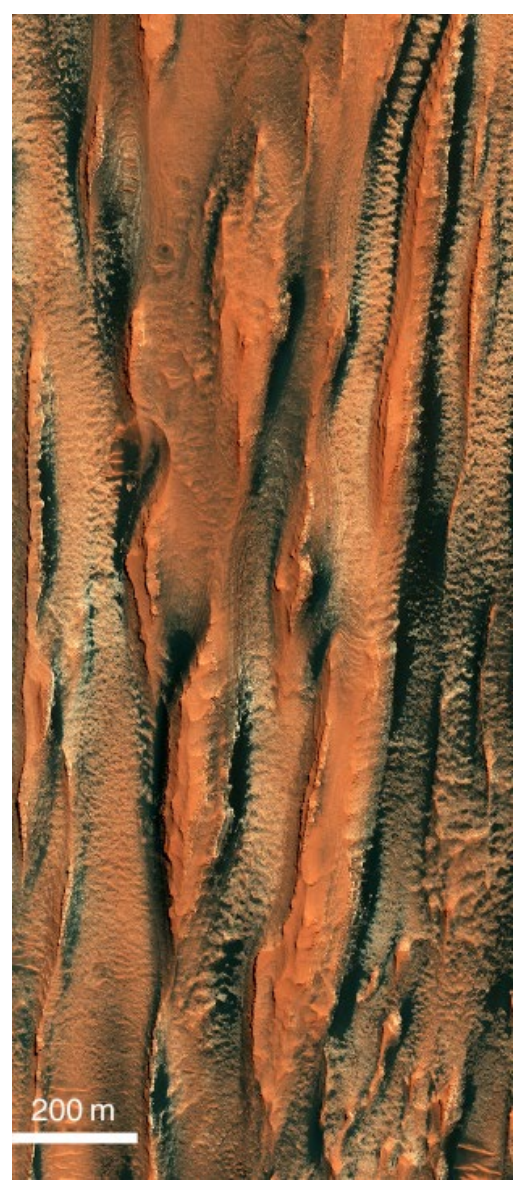

Figure 11.11 Yardangs on Mars. Section of HiRISE image ESP_023051_1865. North is towards top of image. See insert for colour representation of this figure.

Yardangs on Mars are larger in scale than those on Earth. Ward (1979) identified individual ridges in the equatorial region of Mars that were tens of kilometres long, with valleys nearly $1 \mathrm{~km}$ wide. These mega-yardangs cover approximately $7 \%$ of the MFF. Their width ranges from $1-5 \mathrm{~km}$ and they range in height from 5-700 $\mathrm{m}$, with most being in excess of $100 \mathrm{~m}$ tall (Mandt et al. 2008). Mega-yardangs on Earth may be tens of metres high and several kilometres long (e.g. Cooke et al. 1993). On Earth, the presence of an upper indurated facies can result in large, high aspect ratio $(1: 20-1: 40)$ mega-yardangs that form $100 \mathrm{~m}$ tall ridges with steep to vertical walls (de Silva et al. 2010). Strong unidirectional winds and a lithology with a vertical induration profile are also proposed to result in the mega-yardang formation in the MFF (Mandt et al. 2009). Yardangs on Mars are also complex in pattern as they can be both parallel and bidirectional. Resistant layers and jointing, in addition to prevailing wind directions, are thought to influence their orientation (Bradley et al. 2002).

Only one possible yardang field has been identified on Venus (Greeley et al. 1992; Greeley et al. 1997) at $9^{\circ} \mathrm{N}, 60.5^{\circ} \mathrm{E}$, about $300 \mathrm{~km}$ south-east of the crater Mead. Because yardangs require an easily-erodable substrate such as lake sediments or ignimbrites, it may be worth considering that such substrates may not be widespread on Venus - with no hydrology for the last several billion years, lake deposits seem unlikely, and the high pressure on Venus makes gassy explosive eruptions on Venus difficult. As with the relative paucity of sand dunes on Venus, the transport of appropriately-sized sediment may not be the limiting factor, but rather the availability of abrading or abradable material. It should also be noted that most terrestrial yardangs would be invisible to Magellan's rather coarse imaging resolution of $\sim 100 \mathrm{~m}$.

On Titan, a handful of locales beyond the main dunefields have been identified with linear features with positive relief. These may be fossil dunes (they have a different orientation from the main equatorial dunes, and a different radar texture) although yardangs cannot be excluded (Paillou et al. 2016).

\subsection{Conclusion}

Evidence for the wind abrasion of rocks and the generation of soil particles has been documented on several bodies in our solar system. In particular, sand dunes with forms very similar to those on Earth have been confirmed on Mars, Venus, and Titan, and bedforms have been proposed on the comet 67P/ Churyumov-Gerasimenko and Pluto (Jia et al. 2017, Telfer et al. 2018). In all these places 
aeolian deposits provide a proxy for regional wind regimes and the availability of sediment, largely because of the understanding we have of aeolian landscapes on Earth (see Chapter 6). As international space programmes extend our exploration to the edge of, and beyond our solar system, we can expect to expand our

\section{Further Reading}

A good introduction to dune systems on planetary bodies in our solar system will be found in Bourke et al. (2010). This review was updated by Zimbelman et al. (2013) and Fenton et al. (2013). A more recent review by Diniega et al. (2017) includes other planetary bodies such as Pluto and Io. For further reading on sediment transport that includes a

\section{References}

Almeida, M.P., Parteli, E.J.R., Andrade, J.S., and Herrmann, H.J. (2008). Giant saltation on Mars. Proceedings of the National Academy of Sciences 105 (17): 6222-6226. doi: 6210.1073/pnas.0800202105.

Anderson, R.S. (1987). A theoretical model for aeolian impact ripples. Sedimentology 34 (5): 943-956. doi: 10.1111/j.1365-3091.1987. tb00814.x.

Andreotti, B., Claudin, P., and Pouliquen, O. (2010). Measurements of the aeolian sand transport saturation length. Geomorphology 123 (3-4): 343-348. doi: 10.1016/j. geomorph.2010.08.002.

Andreotti, B., Fourriere, A., Ould-Kaddour, F. et al. (2009). Giant aeolian dune size determined by the average depth of the atmospheric boundary layer. Nature 457 (7233): 1120-1123. doi: 1110.1038/ nature07787.

Arvidson, R.E., Guinness, E.A., Moore, H.J. et al. (1983). Three Mars years: Viking Lander 1 imaging observations. Science 222 (4623): 463-468. doi: 10.1126/science.222. 4623.463. perception of aeolian geomorphology. The challenge is to continue to develop image and analytical tools that allow us to understand the full range of controls that permit aeolian geomorphology to operate in environments that are different to those on Earth.

planetary perspective, we recommend Kok et al. (2012). For specific topics, such as Martian dune migration, we recommend Bridges et al. (2013). A recent book on the topic of planetary dunes that includes analogue research and methods is Lorenz and Zimbelman (2014).

Ayoub, F., Avouac, J.P., Newman, C.E. et al. (2014). Threshold for sand mobility on Mars calibrated from seasonal variations of sand flux. Nature Communications 5: 5096. doi: 10.1038/ncomms6096.

Bagnold, R.A. (1941). The Physics of Blown Sand and Desert Dunes. London: Methuen.

Balme, M.R., Berman, D., Bourke, M.C., and Zimbelman, J.R. (2008). Transverse aeolian ridges (TARs) on Mars. Geomorphology 101 (4): 703-720. doi: 710.1016/j.geomorph. 2008.1003.1011.

Balme, M.R., Gallagher, C.J., and Hauber, E. (2013). Morphological evidence for geologically young thaw of ice on Mars: a review of recent studies using highresolution imaging data. Progress in Physical Geography 37 (3): 289-324. doi: $10.1177 / 0309133313477123$.

Balme, M.R. and Greeley, R. (2006). Dust devils on Earth and Mars. AGU100.

Barnes, J., Lorenz, R., Radebaugh, J. et al. (2015). Production and global transport of Titan's sand particles. Planetary Science 4 (1): doi: 10.1186/s13535-015-9-0004-y. 
Blasius, K.R., Cutts, J.A., and Howard, A.D. (1982). Topography and stratigraphy of Martian polar layered deposits. Icarus 50 (2-3): 140-160. doi: 10.1016/0019-1035 (82)90122-1.

Bourke, M.C., Bullard, J., and Barnouin-Jha, O. (2004). Aeolian sediment transport pathways and aerodynamics at troughs on Mars. Journal of Geophysical Research (Planets) 109 (E7): E07005. doi: 10.1029/2003JE002155.

Bourke, M.C., Lancaster, N., Fenton, L.K. et al. (2010). Extraterrestrial dunes: an introduction to the special issue on planetary dune systems. Geomorphology 121 (1-2): 1-14. doi: 10.1016/j. geomorph.2010.1004.1007.

Bourke, M.C., Wilson, A.A., and Zimbelman, J.R. (2003). The Variability of Transverse Aeolian Ridges in Troughs on Mars. Lunar and Planetary Science Conference, p. 2090.

Bradley, B.A., Sakimoto, S.E.H., Frey, H., and Zimbelman, J.R. (2002). Medusae Fossae Formation: new perspectives from Mars Global Surveyor. Journal of Geophysical Research 107 (E8): 5058. doi: 10.1029/ 2001JE001537.

Bridges, N.T., Ayoub, F., Avouac, J.P. et al. (2012a). Earth-like sand fluxes on Mars. Nature 485 (7398): 339-342. doi: 10.1038/nature11022.

Bridges, N.T., Banks, M.E., Beyer, R.A. et al. (2010). Aeolian bedforms, yardangs, and indurated surfaces in the Tharsis Montes as seen by the HiRISE camera: evidence for dust aggregates. Icarus 205 (1): 165-182. doi: 10.1016/j.icarus.2009.05.017.

Bridges, N.T., Bourke, M.C., Geissler, P.E. et al. (2012b). Planet-wide sand motion on Mars. Geology 40 (1): 31-34. doi: 10.1130/ G32373.1.

Bridges, N.T., Geissler, F., Silvestro, P., and Banks, M. (2013). Bedform migration on Mars: current results and future plans. Aeolian Research 9: 133-151. doi: 10.1016/j. aeolia.2013.02.004.

Bridges, N.T., Greeley, R., Haldemann, A.F.C. et al. (1999). Ventifacts at the Pathfinder landing site. Journal of Geophysical Research
104 (E4): 8595-8615. doi: 10.1029/98JE02550.

Bridges, N.T. and Laity, J.E. (2013).

Fundamentals of Aeolian sediment transport: Aeolian abrasion. In: Treatise on Geomorphology (ed. J.F. Shroder), 134-148. San Diego: Academic Press.

Burr, D., Bridges, N., Marshall, J. et al. (2015). Higher-than-predicted saltation threshold wind speeds on Titan. Nature 517: 60-63.

Charnay, B., Barth, E., Rafkin, S. et al. (2015). Methane storms as a driver of Titan's dune orientation. Nature Geoscience 8 (5): 362-366. doi: 10.1038/ngeo2406.

Claudin, P. and Andreotti, B. (2006). A scaling law for aeolian dunes on Mars, Venus, Earth, and for subaqueous ripples. Earth and Planetary Science Letters 252 (1-2): 30-44. doi: 0.1016/j.epsl.2006.09.004.

Claudin, P., Wiggs, G.F.S., and Andreotti, B. (2013). Field evidence for the upwind velocity shift at the crest of low dunes. Boundary-Layer Meteorology 148: 195-206. doi: 10.1007/s10546-013-9804-3.

Conway, S.J. and Balme, M.R. (2014). Decameter thick remnant glacial ice deposits on Mars. Geophysical Research Letters 41 (15): 5402-5409. doi: 10.1002/2014GL060314.

Cooke, R.U., Warren, A., and Goudie, A.S. (1993). Desert Geomorphology. London: UCL Press Limited.

Cutts, J.A. (1973). Nature and origin of layered deposits of the Martian polar regions. Journal of Geophysical Research 78 (20): 4231-4249. doi: 10.1029/JB078i020p04231.

De Silva, S.L., Bailey, J.E., Mandt, K.E., and Viramonte, J.M. (2010). Yardangs in terrestrial ignimbrites: synergistic remote and field observations on Earth with applications to Mars. Planetary and Space Science 58 (4): 459-471. doi: 10.1016/j. pss.2009.10.002.

Diniega, S., Kreslavsky, M., Radebaugh, J. et al. (2017). Our evolving understanding of aeolian bedforms, based on observation of dunes on different worlds. Aeolian Research doi: 10.1016/j.aeolia.2016.10.001. 
Durán, O., Parteli, E.J.R., and Herrmann, H.J. (2010). A continuous model for sand dunes: review, new developments and application to barchan dunes and barchan dune fields. Earth Surface Processes and Landforms 35 (13): 1591-1600. doi: 10.1002/esp.2070.

Edgett, K.S. and Christensen, P.R. (1991). The particle size of Martian aeolian dunes. Journal of Geophysical Research, Planets 96 (E5): 22765-22776. doi: 10.1029/91JE02412.

Edgett, K.S., Williams, R.M.E., Malin, M.C. et al. (2003). Mars landscape evolution: influence of stratigraphy on geomorphology in the North polar region. Geomorphology 52 (3-4): 289-297. doi: 10.1016/S0169555X(02)00262-3.

Feldman, W.C., Prettyman, T.H., Maurice, S. et al. (2004). Global distribution of near-surface hydrogen on Mars. Journal of Geophysical Research 109 (E9): doi: 10.1029/2003JE002160.

Fenton, L.K., Ewing, R.C., Bridges, N.T., and Lorenz, R. (2013). Extraterrestrial aeolian landscapes. In: Treatise on Geomorphology (ed. J.F. Shroder), 287-312. San Diego: Academic Press.

Fenton, L.K. and Hayward, R.K. (2010). Southern high-latitude dune fields on Mars: morphology, aeolian activity and climate change. Geomorphology 121 (1-2): 98-121. doi: 110.1016/j.geomorph.2009.1011.1006.

Flasar, F.M., Baines, K.H., Bird, M.K. et al. (2010). Atmospheric dynamics and meteorology. In: Titan from CassiniHuygens (ed. R.H. Brown, J.P. Lebreton and J. Waite), 323-353. Berlin: Springer Science.

Fourrière, A., Claudin, P., and Andreotti, B. (2010). Bedforms in a turbulent stream: formation of ripples by primary linear instability and of dunes by nonlinear pattern coarsening. Journal of Fluid Mechanics 649: 287-328. doi: doi.org/10.1017/ S0022112009993466.

Franklin, E.M. and Charru, F. (2011). Subaqueous barchan dunes in turbulent shear flow. Part 2: Fluid flow. Journal of Fluid Mechanics 675: 199-222.

Geissler, P.E. (2014). The birth and death of transverse aeolian ridges on Mars. Journal of
Geophysical Research, E: Planets 119: 2583-2599. doi: 10.1002/2014JE004633.

Gillette, D.A. and Sinclair, P.C. (1990). Estimation of suspension of alkaline material by dust devils in the United-States. Atmospheric Environment. Part A. General Topics 24 (General Topics 24): 1135-1142.

Greeley, R., Arvidson, R.E., Elachi, C. et al. (1992). Aeolian features on Venus: preliminary Magellan results. Journal of Geophysical Research, Planets 97 (E8): 13319-13345. doi: 10.1029/92JE00980.

Greeley, R., Bender, K., Saunders, R.S. et al. (1997). Aeolian processes and features on Venus. In: Venus II (ed. S.W. Gougher, D.M. Hunten and R.J. Phillips), 547-589. Tucson: University of Arizona Press.

Greeley, R., Bender, K., Thomas, P.E. et al. (1995). Wind-related features and processes on Venus: summary of Magellan result. Icarus 11 (2): 399-420. doi: 10.1006/icar.1995.1107.

Greeley, R. and Iversen, J.D. (1985). Wind as a Geological Process on Earth, Mars, Venus and Titan. Cambridge: Cambridge University Press.

Greeley, R., Squyres, S.W., Arvidson, R.E. et al. (2004). Wind-related processes detected by the Spirit Rover at Gusev Crater, Mars. Science 305 (5685): 810-821. doi: 10.1029/92JE02580.

Grotzinger, J.P., Arvidson, R.E., Bell, J.F. et al. (2005). Stratigraphy and sedimentology of a dry to wet eolian depositional system, burns formation, Meridiani Planum, Mars. Earth and Planetary Science Letters 240 (1): 11-72. doi: 10.1016/j.epsl.2005.09.039.

Grotzinger, J.P., Hayes, A.G., Lamb, M.P., and McLennan, S.M. (2013). Sedimentary processes on earth, Mars, titan, and Venus. In: Comparative Climatology of Terrestrial Planets (ed. S.J. Mackwell, A.A. Simon-Miller, J.W. Harder and M.A. Bullock), 439-472. Tucson: University of Arizona Press.

Hayward, R., Mullins, K., Fenton, L.K. et al. (2007). Mars Digital Dune Database: MC2-MC29. USGS Open-File Report.

Head, J.W., Mustard, J.F., Kreslavsky, M.A. et al. (2003). Recent ice ages on Mars. Nature 426: 797-802. doi: 10.1038/nature0211. 
Hersen, P., Douady, S., and Andreotti, B. (2002). Relevant length scale of barchan dunes. Physical Review Letters 89: 264301. doi: 10.1103/PhysRevLett.89.264301.

Holstein-Rathlou, C., Gunnlauggson, H.P., Merrison, J.P. et al. (2010). Winds at the Phoenix landing site. Journal of Geophysical Research, Planets 115 (E00E18): doi: 10.1029/2009JE003411.

Iversen, J.D. and White, B.R. (1982). Saltation threshold on Earth, Mars and Venus. Sedimentology 29 (1): 111-119. doi: 10.1111/ j.1365-3091.1982.tb01713.x.

Jackson, D.W.T., Bourke, M.C., and Smyth, T. (2015). The dune effect on sand transporting winds on Mars. Nature Communications 9796 (2015): doi: $10.1038 /$ ncomms9796.

Jia, P., Andreotti, B., and Claudin, P. (2017). "Giant ripples on comet 67P/ChuryumovGerasimenko sculpted by sunset thermal wind." Proceedings of the National Academy of Sciences 114 (10): 2509-2514.

Kahn, R.A., Martin, T.Z., Zurek, R.W., and Lee, S.W. (1992). The Martian dust cycle. In: Mars (ed. H. Kieffer, B.M. Jakosky, C.W. Snyder and M.S. Matthews), 1017-1053. Tucson: University of Arizona Press.

Kinch, K.M., Sohl-Dickstein, J., Bell, J.F. III et al. (2007). Dust deposition on the Mars Exploration Rover Panoramic Camera (Pancam) calibration targets. Journal of Geophysical Research, Planets 112: E06S03. doi: 10.1029/2006JE002807.

Kok, J.F. (2010a). Difference in the wind speeds required for initiation versus continuation of sand transport on Mars: implications for dunes and dust storms. Physical Review Letters 104: 074502. doi: 10.1103/ PhysRevLett.104.074502.

Kok, J.F. (2010b). An improved parameterization of wind-blown sand flux on Mars that includes the effect of hysteresis. Geophysical Research Letters 37: L12202. doi: 10.1029/2010GL043646.

Kok, J.F., Parteli, E.J.R., Michaels, T.I., and Karam, D.B. (2012). The physics of windblown sand and dust. Reports on Progress in Physics 75: 106901. doi: 10.1088/0034-4885/75/10/106901.
Kreslavsky, M.A. and Head, J.W. (2002). Mars: nature and evolution of young latitudedependent water-ice-rich mantle. Geophysical Research Letters 29 (15): 14-21. doi: 10.1029/2002GL015392.

Kroy, K., Sauermann, G., and Herrmann, H.J. (2002). Minimal model for aeolian sand dunes. Physical Review. E, Statistical, Nonlinear, and Soft Matter Physics 66: 031302. doi: 10.1103/PhysRevE.66.031302.

Laskar, J., Correia, A.C.M., Gastineau, M. et al. (2004). Long term evolution and chaotic diffusion of the insolation quantities of Mars. Icarus 170 (2): 343-364. doi: 10.1016/j.icarus.2004.04.005.

Le Gall, A., Janssen, M.A., Wye, L.C. et al. (2011). Cassini SAR, radiometry, scatterometry and altimetry observations of Titan's dune fields. Icarus 213 (2): 608-624. doi: 10.1016/j.icarus.2011.03.026.

Livingstone, I. and Warren, A. (1996). Aeolian Geomorphology: An Introduction. London: Longman.

Lorenz, R.D., Lunine, J.I., Grier, J.A., and Fisher, M.A. (1995). Prediction of aeolian features on planets: application to Titan paleoclimatology. Journal of Geophysical Research 100: 26377-26386.

Lorenz, R.D. and Myers, M.J. (2005). Dust devil hazard to aviation. A review of United States air accident reports. The Journal of Meteorology (Trowbridge) 30 (299): 178-183.

Lorenz, R.D. and Zimbelman, J.R. (2014). Dune Worlds: How Windblown Sand Shapes Planetary Landscapes. London: Springer.

Lorenz, R.D., Wall, S., Radebaugh, J. et al. (2006). The sand seas of Titan: Cassini RADAR observations of longitudinal dunes. Science 312 (5774): 724-727. doi: 10.1126/ science.1123257.

Lorenz, R., Claudin, P., Andreotti, B., Radebaugh, J., and Tokano, T. (2010). "A $3 \mathrm{~km}$ atmospheric boundary layer on Titan indicated by dune spacing and Huygens data." Icarus 205: 719-721.

Lorenz, R.D., Bridges, N.T., Rosenthal, A.A., and Donkor, E. (2014). Elevation dependence of bedform wavelength on Tharsis Montes, Mars: atmospheric density 
as a controlling parameter. Icarus 230: 77-80. doi: 10.1016/j.icarus.2013.10.026.

Lucas, A., Rodriguez, S., Narteau, C. et al. (2014). Growth mechanisms and dune orientation on Titan. Geophysical Research Letters 41 (17): 6093-6100. doi: 10.1002/ 2014 GL060971.

Mandt, K.E., de Silva, S.L., Zimbelman, J.R., and Crown, D.A. (2008). Origin of the Medusae Fossae Formation, Mars: insights from a synoptic approach. Journal of Geophysical Research, Planets 113 (E12): doi: 10.1029/2008JE003076.

Mandt, K., de Silva, S., Zimbelman, J., and Wyrick, D. (2009). Distinct erosional progressions in the Medusae Fossae Formation, Mars, indicate contrasting environmental conditions. Icarus 204 (2): 471-477. doi: 10.1016/j.icarus.2009.06.031.

Marshall, J.R. and Stratton, D. (1999). Computer modeling of sand transport on Mars using a compartmentalized fluids algorithm (CFA). Proceedings of the Lunar and Planetary Science Conference 30: 1229.

Massé, M., Bourgeois, O., Le Mouélic, S. et al. (2010). Martian polar and circum-polar sulfate-bearing deposits: sublimation tills derived from the North Polar Cap. Icarus 209 (2): 434-451. doi: 10.1016/j.icarus.2010.04.017. McCauley, J.F. (1973). Mariner 9 evidence for wind erosion in the equatorial and midlatitude regions of Mars. Journal of Geophysical Research 78 (20): 4123-4137. doi: 10.1029/JB078i020p04123.

Mitchell, J.L. (2008). The drying of Titan's dunes: Titan's methane hydrology and its impact on atmospheric circulation. Journal of Geophysical Research, Planets 113: E08015. doi: 10.1029/2007JE003017.

Moore, H.J. (1985). The Martian dust storm of sol 1742. In: Proceedings of the 16th Lunar and Planetary Science Conference, I. Journal of Geophysical Research: Atmospheres 90(D, Supplement): 163-174, doi:10.1029/ JB090iS01p00163.

Mulholland, D.P., Read, P.L., and Lewis, S.R. (2013). Simulating the interannual variability of major dust storms on Mars using variable lifting thresholds. Icarus 223 (1): 344-358. doi: 10.1016/j.icarus.2012.12.003.
Mustard, J.F., Cooper, C.D., and Rifkin, M.K. (2001). Evidence for recent climate change on Mars from the identification of youthful near-surface ground ice. Nature 412: 411414. doi: 10.1038/35086515.

Newman, C.E., Lewis, S.R., Read, P.L., and Forget, F. (2002). Modeling the Martian dust cycle, 1 . Representations of dust transport processes. Journal of Geophysical Research, Planets 107 (E12): 5123. doi: 10.1029/2002JE001910.

Ojha, L., Wilhelm, M.B., Murchie, S.L. et al. (2015). Spectral evidence for hydrated salts in recurring slope lineae on Mars. Nature Geoscience, advance online publication doi: 10.1038/ngeo2546.

Pähtz, T., Kok, J.F., Parteli, E.J.R., and Herrmann, H.J. (2013). Flux saturation length of sediment transport. Physical Review Letters 111: 218002. doi: 10.1103/ PhysRevLett.111.218002.

Paillou, P., Seignovert, B., Radebaugh, J., and Wall, S. (2016). Radar scattering of linear dunes and mega-yardangs: application to Titan. Icarus 270: 211-221. doi: 10.1016/j. icarus.2015.07.038.

Parteli, E.J.R., Durán, O., and Herrmann, H.J. (2007). Minimal size of a barchan dune. Physical Review. E, Statistical, Nonlinear, and Soft Matter Physics 75: 011301. doi: 10.1103/PhysRevE.75.011301. (Comment: Andreotti, B. and Claudin, P. 2008. PRE- SNSMP 76, 063302, doi:10.1103/ PhysRevE.76.063302. Reply P.D.H. 2008. PRE- SNSMP76, 063302, doi:10.1103/ PhysRevE.76.063302).

Parteli, E.J.R. and Herrmann, H.J. (2007). Dune formation on the present Mars. Physical Review. E, Statistical, Nonlinear, and Soft Matter Physics 76: 041307. doi: 10.1103/ PhysRevE.76.041307.

Radebaugh, J., Lorenz, R.D., Farr, T. et al. (2010). Linear dunes on Titan and Earth: initial remote sensing comparisons. Geomorphology 121 (1-2): 122-132. doi: 10.1016/j.geomorph.2009.02.022.

Read, P.L. and Lewis, S.R. (2004). The Martian Climate Revisited: Atmosphere and Environment of a Desert Planet. Berlin: Springer. 
Reffet, E., Courrech du Pont, S., Hersen, P., and Douady, S. (2010). Formation and stability of transverse and longitudinal sand dunes.

Geology 38 (6): 491-494. doi: 10.1130/ G30894.1.

Silvestro, S., Vaz, D.A., Ewing, R.C. et al. (2013). Pervasive aeolian activity along rover Curiosity's traverse in Gale Crater, Mars. Geology 41 (4): 483-486. doi: 10.1130/ G34162.1.

Skinner, J.A. Jr., Tanaka, K.L., and Platz, T. (2012). Widespread loess-like deposit in the Martian northern lowlands identifies middle Amazonian climate change. Geology 40 (12): 1127-1130. doi: 10.1130/G33513.1.

Sullivan, R., Arvidson, R., Bell, J.F. et al. (2008). Wind-driven particle mobility on Mars: insights from Mars Exploration Rover observations at "El Dorado" and surroundings at Gusev Crater. Journal of Geophysical Research, Planets 113: E06S07. doi: 10.1029/2008JE003101.

Sullivan, R., Banfield, D., Bell, J.F. et al. (2005). Aeolian processes at the Mars Exploration Rover Meridiani Planum landing site. Nature (London) 436 (7047): 58-61. doi: 10.1038/nature03641.

Sullivan, R., Greeley, R., Kraft, M. et al. (2000). Results of the imager for Mars Pathfinder windsock experiment. Journal of Geophysical Research 105 (E10): 24547-24562. doi: 10.1029/1999JE001234.

Sutton, J.L., Leovy, C.B., and Tillman, J.E. (1978). Diurnal variations of the Martian surface layer meteorological parameters during the first 45 sols at two Viking Lander sites. Journal of the Atmospheric Sciences 35 (12): 2346-2355. doi: 10.1175/1520-0469 (1978)035<2346:DVOTMS>2.0.CO;2.

Tanaka, K.L. (2000). Dust and ice deposition in the Martian geologic record. Icarus 144 (2): 254-266. doi: 10.1006/icar.1999.6297.

Taylor, K.C., Lamorey, G.W., Doyle, G.A. et al. (1993). The "flickering switch" of late Pleistocene climate change. Nature 361: 432-436. doi: 10.1038/361432a0.
Telfer, M.W., Parteli, E.J.R. Radebaugh, J., Beyer, R.A., Bertrand, T., Forget, F., Nimmo, F., Grundy, W.M., Moore, J.M., Stern, S.A., Spencer, J., Lauer, T.R., Earle, A.M., Binzel, R.P., Weaver, H.A., Olkin, C.B., Young, L.A., Ennico, K., and Runyon, K. (2018). "Dunes on Pluto." Science 360 (6392): 992-997.

Thomson, B.J., Bridges, N.T., and Greeley, R. (2008). Rock abrasion features in the Columbia Hills, Mars. Journal of Geophysical Research, Planets 113: E08010. doi: 10.1029/2007JE003018.

Tirsch, D., Jaumann, R., Pacifici, A., and Poulet, F. (2011). Dark aeolian sediments in Martian craters: composition and sources. Journal of Geophysical Research, Planets 116 (E03002): doi: 10.1029/2009JE003562.

Tokano, T. (2008). Dune-forming winds on Titan and the influence of topography. Icarus 194 (1): 243-262. doi: 10.1016/j.icarus.2007.10.007.

Tokano, T. (2010). Relevance of fast westerlies at equinox for the eastward elongation of Titan's dunes. Aeolian Research 2 (2-3): 113-127. doi: 10.1016/j.aeolia.2010.04.003.

Ward, A.W. (1979). Yardangs on Mars: evidence of recent wind erosion. Journal of Geophysical Research: Solid Earth 84 (B14): 8147-8166. doi: 10.1029/JB084iB14p08147.

Wolff, M.J. (2003). Constraints on the size of Martian aerosols from Thermal Emission Spectrometer observations. Journal of Geophysical Research, Planets 108 (E9): 5097. doi: 10.1029/2003JE002057.

Wolff, M.J., Smith, M.D., Clancy, R.T. et al. (2006). Constraints on dust aerosols from the Mars Exploration Rovers using MGS overflights and mini-TES. Journal of Geophysical Research, Planets 111: E12S17. doi: 10.1029/2006JE002786.

Zimbelman, J.R., Bourke, M.C., and Lorenz, R.D. (2013). Recent developments in planetary Aeolian studies and their terrestrial analogs. Aeolian Research 11: 109-126. doi: doi.org/10.1016/j.aeolia.2013.04.004.

Zurek, R.W. and Martin, L.J. (1993). Interannual variability of planet-encircling dust storms on Mars. Journal of Geophysical Research, Planets 98 (E2): doi: 10.1029/1092JE02936. 